The Trickle-Down Effects of Perceived Trustworthiness on Subordinate Performance 


\begin{abstract}
We study when and why perceptions of trustworthiness trickle down the organizational hierarchy to influence the performance of subordinates. Building on social learning theory, we argue that when supervisors perceive their managers as trustworthy, subordinates are more likely to also perceive their supervisor as trustworthy, which in turn enhances subordinate performance. We further argue that this trickle-down effect of trustworthiness perceptions emerges especially when the manager invites the supervisor to participate in decision-making. Finally, we propose that social learning processes that lead to supervisors exhibiting more trusting behavior toward their subordinates mediate this trickle-down effect. We find support for our predictions across one multisource field study (Study 1) and two experiments (Studies 2 and 3) that both employ a yoked design. This research represents the first attempt to examine trickle-down effects related to trustworthiness, its impact on performance, and the mediating mechanisms by which those effects emerge. This research also provides the first empirical evidence about the role that social learning processes play in explaining trickle-down processes.
\end{abstract}

Key words: Trust, Trustworthiness, Trickle Down, Participation, Performance, Social Learning Theory 


\section{The Trickle-Down Effects of Perceived Trustworthiness on Subordinate Performance}

The existence of trusting relationships is critical for the effective functioning of organizations (Dirks \& Ferrin, 2001; Kramer, 1999). There are many benefits when organizational members trust their colleagues and managers, including higher organizational commitment, more cooperation and citizenship behaviors, and better individual job performance (Colquitt, Scott, \& LePine, 2007; Dirks \& Ferrin, 2002). In turn, these variables stimulate the performance of the organization (e.g., Gelade \& Ivery, 2003; Podsakoff, Whiting, Podsakoff, \& Blume, 2009).

In the organizational behavior literature two dominating definitions of trust exist. First, Rousseau, Sitkin, Burt, and Camerer (1998) defined trust as "a psychological state comprising the intention to accept vulnerability based upon positive expectations of the intentions or behavior of another" p. 395). Second, Mayer, Davis, and Schoorman (1995) defined trust as "willingness to be vulnerable to the actions of another party based on the expectation that the other will perform a particular action important to the trustor" (p. 712). Both definitions emphasize the same two primary components that make up trust, which are the intention to accept vulnerability (e.g., Boon \& Holmes, 1991; Govier, 1994; Zand, 1972) and positive expectations about one's interaction partner (e.g., Barber, 1983; Cook \& Wall, 1980; Roberts \& O’Reilly, 1974).

The literature further suggests that perceptions of trustworthiness of another party which reflect judgments about the extent to which one perceives the other person as trustworthy, a characteristic that makes them a favourable exchange partner (see Mayer et al., 1995) - are central in understanding the emergence of trust (Colquitt et al., 2007), as these perceptions promote positive expectations that the other party will act in honest and nonexploitative ways (Fulmer \& Gelfand, 2012; Ross \& LaCroix, 1996; M. Williams, 2001). As we will elaborate later, these specific relationships between trust and trustworthiness are 
important for the development of our conceptual model.

So far, the research literature on trust development has primarily focused on the development of interpersonal trust as based on the behaviors, attitudes, and traits of the individuals displayed within specific dyadic interactions (Flores \& Solomon, 1998; Holmes, 1991; Kosfeld, Heinrichs, Zak, Fischbacher, \& Fehr, 2005; Rempel, Holmes, \& Zanna, 1985; Zand, 1972). For example, studies have examined the importance of the trustor's characteristics, such as trust propensity (Rotter, 1967, 1971), and the perceived characteristics of the trustee, such as integrity, benevolence, and ability (Mayer et al., 1995), as antecedents of how interpersonal trust develops (Colquitt et al., 2007; Lewicki, Tomlinson, \& Gillespie, 2006).

However, trusting relationships develop not only within the constraints of one specific dyadic relationship. Early theoretical work has postulated that interpersonal trust needs to be placed in a social context (Arrow, 1974; Cook \& Hardin, 2001; Kramer, 1999; Read, 1962). Kramer (1996), for example, noted more than two decades ago, "theory on trust and distrust...has remained surprisingly acontextual" (p. 237). In the meantime, this theoretical proposition has received some initial empirical support as well, from studies using network analysis (Ferrin, Dirks, \& Shah, 2006; Gupta, Ho, Pollack, \& Lai, 2016) and trust-transfer perspectives (Fulmer \& Ostroff, 2017) to demonstrate that the effects of interpersonal trust are indeed socially embedded.

In the present paper, we echo the message of these studies with respect to the importance of examining the development of interpersonal trust as nested within a rich social context. We do so by following the assumption of Colquitt et al. (2017), who note that "the concept of trustworthiness [emphasis added] is central to understanding and predicting trust levels" (p. 910). The few studies in previous research that have explored how interpersonal trust develops within a socially embedded environment have also examined the role of 
trustworthiness perceptions (Ferrin et al., 2006; Fulmer \& Ostroff, 2017). In line with these studies, we therefore will focus on how - based on characteristics and behaviors - trustors come to perceive other organizational members as trustworthy (i.e., perceived trustworthiness; Colquitt et al., 2007).

However, in contrast to prior research that looks at the trustworthiness perceptions for a single individual across different interpersonal relationships (Ferrin et al, 2006; Fulmer \& Ostroff, 2017; Gupta et al., 2016), we examine separate sets of perceptions transpiring in the minds of separate individuals at different levels of the organization. ${ }^{1}$ In particular, we investigate how a target person's (i.e., a supervisor) perception of how trustworthy a higherlevel party (i.e., a manager) is influences how trustworthy a lower-level party (i.e., a subordinate) perceives the target person (supervisor) to be. Thus, our research explicitly integrates the hierarchical context in which different interpersonal relationships are situated. That is, we examine how trustworthiness perceptions at higher levels in the organization affect how trustworthiness perceptions develop at lower levels (leader-subordinate relationships) and consequently, how those trustworthiness perceptions impact subordinate performance. In contrast to prior research, therefore, we are interested in how trustworthiness perceptions trickle down the organizational hierarchy, from higher to lower levels (see Fulmer \& Gelfand, 2012 for a similar suggestion), to influence performance.

A trickle-down effect is defined as a process "in which the perceptions, attitudes, or behaviors of one individual (i.e., a manager) influence the perceptions, attitudes or behaviors of a second individual (i.e., a supervisor), which then influence the perceptions, attitudes, or behavior of a third individual (i.e., a subordinate)" (Wo, Ambrose, \& Schminke, 2015; p. 1848). ${ }^{2}$ We employ this trickle-down approach to test whether a supervisor's perception that

\footnotetext{
${ }^{1}$ We use the notion of level to refer to a hierarchical level of management within the organization, which is different from Fulmer and Gelfand (2012), who use the notion of level to refer to the level of analysis of a study.

${ }^{2}$ Fulmer and Ostroff (2017) recently examined interpersonal trust in a hierarchical setting by looking at what they call a trickle-up effect. However, based on the definition of a trickle-down effect presented in the literature
} 
his/her manager is trustworthy will positively affect how trustworthy a subordinate perceives that supervisor to be and whether this will in turn influence subordinate performance.

We draw on social learning theory (Bandura, 1977, 1986) to develop our predictions regarding the emergence of a trickle-down model of trustworthiness perceptions. In doing so, we create a conditional indirect-effects model that illustrates our predictions regarding the pattern by which trustworthiness perceptions trickle down the organizational hierarchy to influence subordinate performance. We do this by specifying both the processes by which that happens (the underlying mediating mechanisms) and the conditions under which those processes will be most pronounced (the moderators of those mediation processes).

Based on social learning theory, we argue that the process by which trustworthiness perceptions trickle down via social learning involves a critical interaction between a supervisor and a manager. We suggest that supervisors are a linking pin between management and subordinates and in this role they are motivated to learn about the way trusting relationships are built in the organization. To create such a learning experience, supervisors actively look at their relationship with their manager (Bandura, 1986).

Specifically, building on the earlier-mentioned alignment between trustworthiness and trust (Colquitt et al., 2007; Fulmer \& Gelfand, 2012), we expect that when supervisors perceive their manager as trustworthy, they hold a positive expectation that the manager will act in ways that justifies this perception (Mayer et al., 1995). We argue that this learning experience can be created by the manager inviting the supervisor to participate in decision-making,

\footnotetext{
(see Wo et al., 2015), the emergence of a trust trickle-up effect would require that a subordinate's trust in his/her supervisor influences the trust that the supervisor has in his/her manager, and so on, up the organizational hierarchy. In other words, just as with a trickle-down effect, a trickle-up effect would involve testing the influence of "perceptions, attitudes or behaviors" across different individuals at different levels of the organizational hierarchy. The Fulmer and Ostroff (2017) paper did not do this. Rather, it explored how a single subordinate's trust in his/her direct supervisor predicted that same subordinate's trust in a higher-level supervisor. In other words, Fulmer and Ostroff examined how the trust judgments of a single employee might generalize across levels. This is an interesting question. However, because they explored a series of trust judgments that are all transpiring in the mind of a single person, it is fair to note that this does not involve a trickle process, at least as it is commonly understood in the trickle literature.
} 
which will activate the existence of a high-trust relationship between manager and supervisor (Jones \& George, 1998). The emergence of this trusting relationship is expected to serve as a basis for the supervisor to learn from, regarding how to act towards his/her own subordinates. This will involve supervisors engaging in trust behavior-behaviorally displaying vulnerability and positive expectations (Mayer et al., 1995) toward subordinates—which will aid in creating a trusting relationship with them. Subordinates will in turn perceive a supervisor who engages in trust behavior as trustworthy, which will then exert a positive effect on the subordinate performance. Figure 1 illustrates our conceptual model (explained in more detail below), and we test the components of this model across three studies.

Our research makes several theoretical contributions. First, by focusing on the impact of the hierarchical setting and employing a trickle-down paradigm, we can examine how one individual's perceptions of trustworthiness at one level influences the trustworthiness perceptions of another individual at a lower level. To the best of our knowledge, we are the first to examine how trustworthiness perceptions trickle down through individuals at various hierarchical levels. We further contribute to the trust and trickle-down literatures by identifying how engaging in trust behavior facilitates the trickling down of trustworthiness perceptions to ultimately influence subordinate performance. Building on the two dominant definitions of trust in the literature that we noted earlier, we conceptualize the behavioral engagement to trust by focusing on the behavioral displays of vulnerability (Kramer, 1999) and positive expectations (Mayer et al., 1995). Our approach is therefore an integrative one because we examine how trust behavior mediates the trickling down of trustworthiness perceptions.

Second, we build on social learning theory (Bandura, 1986) to craft our prediction regarding the dynamic interplay between trust behavior and trustworthiness perceptions at different levels (see also Fulmer \& Gelfand, 2012). Although prior work has used social 
learning theory as a guiding theoretical framework for trickle-down effects, it has not been empirically verified that social learning is the actual mediating mechanism by which trickledown effects emerge. As Wo and colleagues (2015, p. 1849) noted recently regarding our theoretical understanding of trickle effects, "none of the existing research empirically examines the proposed [theoretical] processes." Wo et al.'s (2015) study provided the first solid evidence of the specific mediating mechanisms involved in trickle-down processes. Interestingly, it showed that social exchange rather than social learning processes mediated justice trickle-down effects. In the present study, we provide empirical evidence regarding the mechanism that drives trust trickle-down effects and our results diverge strongly from the findings of Wo et al. (2015). Specifically, we provide direct empirical evidence that social learning processes are the driving mechanism by which supervisors are motivated to act in trusting ways toward subordinates who then, in turn, perceive the supervisor as trustworthy. These results thus represent an important contribution to the trickle-down literature and illustrate that different processes underlie the trickle-down effects of different (but related) concepts like trustworthiness and justice.

Finally, prior research has revealed evidence that perceiving leaders as trustworthy is positively associated with subordinate performance (Dirks, 2000; Dirks \& Ferrin, 2001; Dirks \& Skarlicki, 2009; Earley, 1986; Gupta et al., 2016; Li \& Tan, 2013; cf. Mayer \& Gavin, 2005). However, it is fair to note that research in this area has also produced mixed findings and therefore scholars agree that performance resulting from trust should be addressed more in future research (see De Jong et al., in press; Fulmer \& Gelfand, 2012). By employing a trickle-down paradigm, we introduce a direct (supervisor-subordinate) and indirect (manager-subordinate) relationship between the presence of interpersonal trust and individual performance. In this manner, our studies also aim to contribute to the trust literature by presenting a deeper understanding of specific mechanisms that allow 
trustworthiness perceptions to trickle down from the supervisor-manager level to the subordinate level and in turn, to individual subordinate performance.

\section{A Trickle-Down Model of Trustworthiness Perceptions}

Masterson (2001) employed the trickle-down approach for the first time by showing in a cross-sectional study that teachers' perceptions of the procedural and distributive justice they experienced on the job predicted their treatment of their own students. In turn, teachers' treatment of students predicted higher justice perceptions on the part of students as well as more positive reactions toward the teacher and the university. Trickle-down effects have also been studied with respect to perceptions of procedural justice (Tepper \& Taylor, 2003), interpersonal and informational justice (Ambrose, Schminke, \& Mayer, 2013; Wo et al., 2015), perceived organizational support (Shanock \& Eisenberger, 2006), behavioral integrity (Simons, Friedman, Liu, \& Parks, 2007), ethical leadership (Mayer, Kuenzi, Greenbaum, Bardes, \& Salvador, 2009), psychological contracts (Bordia, Restubog, Bordia, \& Tang, 2010), organizational identity (Schuh, Zhang, Egold, Graf, Pandey, \& van Dick, 2012), and abusive supervision (Mawritz, Mayer, Hoobler, Wayne, \& Marinova, 2012). However, to date, no empirical research has examined the trickling down of trustworthiness perceptions (or any other aspect of trust) within organizations.

Our trickle-down model of perceived trustworthiness rests on social learning theory (Bandura, 1977, 1986), which states that individuals learn how to behave by observing the behaviors of role models, particularly those who have power and high status. In the context of our present research, this idea suggests that "a supervisor is likely to look to his or her manager to learn the appropriate way to interact with others" (Ambrose et al., 2013). Important to our present research question, social learning theory also postulates that people (i.e. the supervisor in our research) will be motivated to learn from the behavior of a role model (i.e. the manager in our research) if that role model meets their expectations. This 
raises the question of how these social learning assumptions apply to how trustworthiness perceptions can trickle down.

We start from the assumption that supervisors are a linking pin between management and subordinates (Bryant \& Stansaker, 2011; Raes, Heijltjes, Glunk, \& Roe, 2011). In the context of this linking pin role, supervisors are motivated to be active participants in the trustbuilding process by assessing whether other organizational members can be considered trustworthy or not. As suggested by social learning theory (Bandura, 1986), an important way to do this is that supervisors direct their attention to their higher-ranked authority (i.e. their manager) to learn about the reality of trusting relationships in the organization (see also Sniezek \& Van Swol, 2001 Meyerson, Weick, \& Kramer, 1996). In this sense, supervisors are actively involved in the trust-building process by generating jointly shared experiences with their manager that they can use to infer whether they too should act in trusting ways towards others or not (Jones \& George, 1998). Therefore, following Jones and Shah (2016), who demonstrated that the actions and perceptions of the trustor (in our case, the supervisor) are the dominant guiding factors in building trusting relationships (i.e. accounting for about $26 \%$ to $55 \%$ of the variance across the dimensions of perceived trustworthiness), we suggest that the extent to which the supervisor perceives the manager to be trustworthy constitutes the primary input in our proposed trickle-down model (see Figure 1).

The trust literature suggests that if one party (i.e. supervisors) perceives the other party (i.e. manager) as trustworthy, the perceiving party will hold positive expectations about the other party's actions aimed at establishing a trusting interpersonal relationship (see Fulmer \& Gelfand, 2012; Jones \& Shah, 2016). Therefore, we propose that the experience of a trusting relationship between the supervisor and manager will only take active shape if the supervisor observes the manager acting in line with those expectations (e.g., Ferrin \& Dirks, 2003; Korsgaard, Brodt, \& Whitener, 2002; Mayer et al., 1995). In other words, we argue that 
from the perspective of the supervisor, the manager is expected to act in ways that establish a trusting relationship (i.e. in ways that validate supervisor perceptions of manager trustworthiness; Kramer, 1996), which will help the supervisor to learn that those in higher positions aim to build trusting relationships with others at lower levels. This in turn motivates the supervisor to do the same towards his/her subordinates. Which actions should the manager display?

As managers make decisions that have consequences for those at lower levels in the organization (Mayer \& Gavin, 2005), one of the most effective ways to establish a trusting relationship is to have these decision processes take the shape of a shared experience rather than a top-down only approach. Indeed, research shows that if decision-making is controlling rather than shared, trust between parties cannot be established (Bernardin, Richey, \& Castro, 2011). Moreover, in a relationship with a higher-level authority, fairness issues are very salient to lower-level parties, and as such trust between parties has been shown to develop the most by justice-related actions (Colquitt et al., 2007). Therefore, it follows that a highly trusting relationship between managers and supervisors is established most effectively by fostering a sense of justice, which is achieved by inviting supervisors to participate in decision-making.

Participation requests from management include asking for a supervisor's help and opinion on organizational matters, and this act of giving voice to supervisors reflects participation as defined in the procedural justice literature (Folger, 1977; van den Bos, 1999). This type of managerial behaviour has consistently been found to influence the development of interpersonal trust (Dirks \& Ferrin, 2002; Gillespie \& Mann, 2004; Huang, Iun, Liu, \& Gong, 2010; Korsgaard, Schweiger, \& Sapienza, 1995). Important to note for our present research effort, however, is that although being given the opportunity to participate in decision-making influences perceived trustworthiness of the inviting party, research suggests 
that participation itself cannot be considered a form of trust behavior. Experimental and field research by De Cremer and Tyler (2007), for example, demonstrated that participation in decision-making and perceiving the enacting authority as trustworthy were independent variables and interacted in predicting prosocial behavior of the lower-level party.

Taken together, we develop the argument that if the supervisor perceives his/her manager as trustworthy, and is being invited to participate in decision-making, then trust will be formed in that relationship between the supervisor and manager. As Lewis and Weigert (1985) noted, “... we cognitively choose whom we will trust in which respects and under which circumstances, and we base the choice on what we take to be "good reasons," constituting evidence of trustworthiness."(p. 970). A good reason in this case is the decision of the manager to invite the supervisor to participate in decision-making, and in combination with the supervisor perceiving the manager as trustworthy, the relationship between the manager and the supervisor will transform into a highly trusting one (Korsgaard, Brower \& Lester, 2015; Lewicki \& Bunker, 1996). In line with our social learning framework, it then follows that if the manager meets the expectations of the supervisor (i.e. following from his or her perceived trustworthiness of the manager) by inviting participation in decision-making, the supervisor will learn that those in higher-level authority roles display trust-building behaviour towards their subordinates. This leads us to the following prediction:

Hypothesis 1: The positive relationship between supervisor perceptions of manager trustworthiness, and the social learning process that emerges from that perception, will be moderated by the level of supervisor participation in decision making, such that the relationship will be stronger when participation is high.

As noted above, the established trust relationship between manager and supervisor will serve as an important guideline for supervisors regarding how to behave towards their own subordinates. Indeed, having one's own positive expectations met by the behavior of the 
manager will enable the supervisor to generalize this experience with the manager to his/her own relationships with subordinates. That is, if perceived trustworthiness is fulfilled, a basis is created to engage in trust behavior oneself (McKnight et al., 1998) and thus build trusting relationships (Colquitt et al., 2007). Moreover, building on our definitions of trust (Mayer et al., 1995; Rousseau et al., 1998) identified earlier, we suggest that the conditions of being willing to be vulnerable towards the actions of others, and displaying positive expectations that others will act in trusting ways, will be the shape in which supervisor trust behavior will be displayed. Therefore, we predict:

Hypothesis 2: The positive relationship between supervisor perceptions of manager trustworthiness, and the supervisor trust behavior toward subordinates that emerges from that perception, will be moderated by the level of supervisor participation in decision making, such that the relationship will be stronger when participation is high.

Building on Hypotheses 1 and 2, it follows that supervisor trust behavior towards subordinates - as a function of the interactive effect between supervisor perceptions of manager trustworthiness and participation - will emerge via the process of social learning. This line of reasoning leads us to predict the following:

Hypothesis 3: The effect of supervisor perceptions of manager trustworthiness on the supervisor trust behavior towards subordinates that emerges from that perception, will be indirect via the mediating mechanism of social learning, and will be moderated by the level of supervisor participation in decision making such that the indirect effect will be stronger when participation is high.

Furthermore, the trust behavior shown by the supervisor towards his/her subordinates is expected to take the shape of displaying willingness to be vulnerable to the actions of the subordinate and expressing a positive expectation that the subordinate can be trusted (Mayer et al., 1995; Mc Knight et al., 1998; Rousseau et al., 1998. These dimensions of vulnerability 
and expectations are the two main dimensions of the process leading people to perceive others as trustworthy (Boon \& Holmes, 1991; Mayer et al., 1995; Roberts \& O’Reilly, 1974; Zand, 1972). As a result, we expect this type of trust behavior displayed by the supervisor to motivate subordinates to perceive their supervisor as trustworthy. Specifically, the more the supervisor shows vulnerability and indicates positive expectations toward the subordinate, the more likely the subordinate will perceive the supervisor as trustworthy (Colquitt et al., 2007). Therefore, we postulate:

Hypothesis 4: The effect of supervisor perceptions of manager trustworthiness on subordinate perceptions of supervisor trustworthiness will be indirect via the mediating mechanism of supervisor trusting behavior toward subordinates, and will be moderated by the level of supervisor participation in decision making such that the indirect effect will be stronger when participation is high.

Finally, research has demonstrated that when subordinates perceive their supervisor as trustworthy, this is positively associated with the subordinate's individual performance (see Colquitt et al., 2007; Dirks \& Ferrin, 2002, for meta-analyses). Therefore, the response of subordinates toward their supervisor, in terms of perceived trustworthiness of the supervisor and their own performance, suggests that supervisor perceptions of manager trustworthiness will exert an indirect influence on the performance of the subordinates via subordinate perceptions of supervisor trustworthiness. The extent to which the supervisor is invited to participate in managerial decision-making will moderate this indirect relationship. This line of reasoning reveals an overall conditional indirect-effects model that predicts the following:

Hypothesis 5. The effect of supervisor perceptions of manager trustworthiness on subordinate performance will be indirect via the mediating mechanism of subordinate perceptions of supervisor trustworthiness, and moderated by the level of supervisor participation in decision making such that the indirect will be stronger when participation is 
high.

\section{The Present Research}

We tested our hypotheses in a multisource field study (Study 1) and two experimental studies (Studies 2a and 2b, and Studies 3a and 3b). In Study 1, we test the validity of our Hypothesis 5. This study provides a field test that demonstrates the role of the trickling down of perceptions of trustworthiness through the organizational hierarchy in predicting a subordinate's performance, particularly when the supervisor is invited to participate in managerial decision-making.

We also wanted to be able to draw causal conclusions about the trickling-down effects of trustworthiness and to test the specific mechanisms we proposed to mediate these trickledown effects (Hypotheses 1, 2, 3 and 4). To this end, we conducted two experiments that both used a yoked design (see e.g., Anicich, Fast, Halevy, \& Galinsky, 2015 for the application of yoked designs in the OB field).

In Study 2, we tested Hypotheses 2 and 4. In Study 2a, we orthogonally manipulated supervisor perception of manager trustworthiness (high vs. low) and management inviting the supervisor to participate in managerial decision-making or not. We operationalized trust behavior by measuring the extent to which the supervisor was willing to be vulnerable to the actions of the subordinate (which is the first of two primary dimensions of trust; Mayer et al., 1995; Rousseau et al., 1998). Subsequently, in Study 2b, we assigned all participants to the role of a subordinate and presented them the actual scores of supervisor trust behavior as assessed in Study 2a. The subordinates responded to these scores in terms of the extent to which they perceived the supervisor as trustworthy.

In Studies 3a and 3b, we tested Hypotheses 1, 2, 3, 4 and 5 using the same manipulations and yoked design as in Studies $2 \mathrm{a}$ and $2 \mathrm{~b}$. The only difference was that in Studies $3 \mathrm{a}$ and $3 \mathrm{~b}$ we measured social learning process as the mediator to be assessed 
(measure taken from Wo et al., 2015). We operationalized supervisor trust behavior toward the subordinate by measuring the extent to which the supervisor wanted to express that he/she considered the subordinate to be trustworthy (i.e., reflecting a positive expectation that giving trust is alright, which is the second primary dimension of trust; Mayer et al., 1995; Rousseau et al., 1998). This is in line with recommendations to test hypotheses across a variety of dependent measures that assess the same basic construct (Meyer, van Witteloostuijn, \& Beugelsdijk, 2017).

\section{Study 1}

We designed Study 1 to test our overall trickle-down model as postulated in Hypothesis 5. Our prediction necessitated testing whether the extent to which supervisor perceptions of manager trustworthiness is indirectly related to subordinate performance, via the subordinate perceptions of supervisor trustworthiness. We also needed to test whether this effect emerges especially strongly when the manager invites the supervisor to participate in decision-making. Our chosen field setting was an educational institute with three hierarchical levels: the principal, the teacher, and the student. These corresponded to higher management, supervisor, and subordinate levels, respectively (see also Erdogan, Liden, \& Kraimer, 2006, for the use of educational settings in field studies). This study allowed us to collect performance data by looking at the exam results of the students.

\section{Method}

Sample and procedure. The respondents were students and teachers from a secondary school in Belgium. At the time of our survey, the school went through several organizational changes, including relocation of classrooms and changes in the digital portfolio that contained student information. Our study items were situated in the context of these changes. We distributed separate surveys to students and teachers. Each survey included a cover letter in which we assured them of the anonymity and confidentiality of their 
responses. We used a unique code to match the responses of the students to those of the teachers. Our design required that each group of students (a class) was assigned to their specific class teacher. This resulted in a sample of 238 students and 26 class teachers.

We included an instrumental attention check to assess whether respondents carefully read our instructions (i.e., "please select "not well' for this statement"; developed by Meade \& Craig, 2012). Twenty-two participants failed to correctly respond to this attention check; therefore, they were excluded from the analyses. Furthermore, in line with Whitson, Wang, Kim, Cao, and Scrimpshire (2015), we also excluded participants who consistently responded to all scale items with the same numerical response (e.g., responding with " 5 " to each item). Based on this criterion, we excluded twenty additional participants. ${ }^{1}$ Our final sample consisted of 196 students and 25 teachers. Of the students, $67.30 \%$ were female, and the mean age was 14.03 years $(S D=1.63)$. Of the teachers, $68.00 \%$ were female, the mean age was 45.44 years $(S D=8.43)$, and the mean organization tenure was 18.48 years $(S D=9.16)$.

Measures. Except when noted otherwise, we measured all items on 7-point scales (1 $=$ strongly disagree to $7=$ strongly agree $)$.

We measured teacher perception of principal trustworthiness with the 3-item scale developed by Brockner, Siegel, Daly, Tyler, and Martin (1997). A sample item is "I can usually trust my supervisor to do what is good for me." Cronbach's $\alpha$ for this sample was $.91 .^{3}$

\footnotetext{
${ }^{3}$ The Brockner et al. (1997) scale is a short instrument that facilitates the administration of a trustworthiness measure to working professionals. More importantly, and in line with McEvily and Tortoriello's (2011) recommendation that the choice for a trust measure should be contingent upon one's research question and model being tested, we used the Brockner et al. (1997) scale for the following reason. The focus of our present research is perceived trustworthiness. According to Mayer et al. (1995), perceived trustworthiness is composed of perceptions on the dimensions of benevolence, integrity, and ability. The Brockner et al. (1997) scale includes items assessing benevolence (promoting the interests of the other) and integrity (adhering to moral values), but not ability. The argument leading to our hypotheses implies that a manager should display behavior contributing to a sense of justice and care in the interaction with the supervisor (i.e. inviting participation). Given this assumption, we focused on the dimensions of integrity and benevolence, which specifically matches our research question. Note that benevolence (Colquitt et al., 2007; Dirks \& Ferrin, 2002; Fulmer \& Gelfand,
} 
We measured student perception of teacher trustworthiness also with Brockner et al.'s (1997) 3-item scale. Cronbach's $\alpha$ for this sample was .87.

We measured teacher participation in principal decision-making by having teachers complete the 3-item participation scale from the Influence Behavior Questionnaire (IBQ; Yukl \& Seifert, 2002). We focused the items on the changes that were being implemented. A sample item is "My supervisor described the change's objective and asked us what we could do to help achieve it." Cronbach's $\alpha$ for this sample was .87 .

The curriculum of the school included four major courses that were mandatory for each student: Mathematics, French, English, and Dutch. In this school setting, a single teacher not only teaches one of these topics but also acts as the general advisor of a specific class. The latter involves supervising all the students in that class throughout the academic year. Thus, we calculated an overall academic performance measure for each student by averaging exam results for each of these four mandatory courses. These four exams took place two months after we collected our survey measures.

\section{Measurement Model}

We conducted confirmatory factor analyses (CFA) using Mplus 6.0 by taking the clustered nature of our sample into account and using robust maximum likelihood estimation. Our initial measurement model contained four factors (i.e., student performance, student perception of teacher trustworthiness, teacher perception of principal trustworthiness, and teacher participation in principal decision-making). This model had a good fit with the data: $\chi^{2}(59)=80.55, p=.03(\mathrm{CFI}=.96, \mathrm{RMSEA}=.04, \mathrm{SRMR}=.06)$. We then tested an alternative three-factor model. The only difference between this model and our first one was that now teacher perception of principal trustworthiness and teacher participation in principal

2012) and integrity (Colquitt et al., 2007; Palanski \& Yammarino, 2009; Simons, 2002) are key predictors of interpersonal trust in other parties, including leaders. 
decision-making were loaded onto one factor. The fit of this model was significantly inferior to that of our proposed model $\left(\chi^{2}(62)=210.87, p=1.19 \times 10^{-07}\right)^{4}$, and the overall fit indices were unacceptable $(\mathrm{CFI}=.69, \mathrm{RMSEA}=.11, \mathrm{SRMR}=.13)$. Then, we tested a three-factor model in which student academic performance and student perception of teacher trustworthiness loaded onto one factor. The fit of this model was also significantly inferior to that of our proposed four-factor model $\left(\chi^{2}(62)=179.15, p=8.35 \times 10^{-20}\right)$, and the overall fit indices were also unacceptable $(\mathrm{CFI}=.76, \mathrm{RMSEA}=.10, \mathrm{SRMR}=.12)$. A final model in which all measures loaded onto one factor also had a significantly inferior fit than our fourfactor model $\left(\chi^{2}(65)=420.61, p=.8 .38 \times 10^{-33}\right)$, and the fit indices were unacceptable by any standard $(\mathrm{CFI}=.27, \mathrm{RMSEA}=.17, \mathrm{SRMR}=.20)$. In sum, the CFAs indicate that our proposed four-factor model fit the data well, and the fit of this model was clearly superior to that of simpler models. This supported the validity of our specified measurement model.

\section{Results}

Descriptive statistics. Table 1 shows all means, standard deviations, and intercorrelations. We mean centered all variables prior to conducting the analyses (Aiken \& West, 1991). We based the Teacher Perception of Principal Trustworthiness $\times$ Teacher Participation in the Principal Decision-Making interaction term on the mean-centered main effects. $^{5}$

Hypothesis testing. As noted above, a single teacher was responsible for a particular class of students during the academic year. Thus, in our data, students were nested within teachers. Because of this nested structure, students from the same class were more likely to

\footnotetext{
${ }^{4}$ Because the measurement models were estimated with a robust estimator, we used the Satorra-Bentler scaled chi-square difference test to assess statistical significance (Satorra \& Bentler, 1988).

${ }^{5}$ In line with recent methodological recommendations (Aguinis, Edwards \& Bradley, 2017; Gardner, Harris, Li, Kirkman \& Mathieu, 2017), we also calculated the reliability of the interaction term that we included in our model (Teachers' Perceptions of Principal's Trustworthiness $\times$ Teacher's Participation in Principal's DecisionMaking) using Busemeyer and Jones' (1983) formula. The reliability of the interaction term was .82.
} 
share certain characteristics or to respond in the same way to our measures compared to students from other classes. As a result, the data did not consist of independent observations, which is required for conducting standard OLS regression (Barcikowski, 1981; MacKinnon, 2008). Indeed, intraclass correlation indices showed that there was a considerable amount of between-group variance on the measures of student perception of teacher trustworthiness $(\operatorname{ICC}[1]=.15)$ and student academic performance $(\operatorname{ICC}[1]=.23)$. However, there was also considerable variance within each group on student perception of teacher trustworthiness $(\operatorname{ICC}[2]=.59)$ and student academic performance $(\operatorname{ICC}[2]=.70)$. Following recent methodological recommendations, we used clustered robust standard errors ( $C R-S E$ 's) to take the clustering of students within class groups into account (McNeish, Stapleton, \& Silverman, 2017).

Table 2 presents the results of the CR-SE regression analysis. ${ }^{6}$ To test our proposed moderated mediation model (see Figure 1; Hypothesis 5), we focused on the paths that constituted the indirect effect (Kenny, Kashy, \& Bolger, 1998; see also Aguinis et al., 2017). The analyses revealed an interaction effect of teacher participation and teacher perception of principal trustworthiness on student perceptions of teacher trustworthiness, $b=0.07, S E=$ $0.02, p=4.93 \times 10^{-05}, d=0.58,95 \% \mathrm{CI}=[0.29,0.86]$, (See Figure 2). Simple slopes tests (Preacher, Curran, \& Bauer, 2006) revealed that teacher perception of principal trustworthiness was positively related to student perception of teacher trustworthiness at high levels of participation $\left(1 S D\right.$ above the mean; $b=0.24, S E=0.06, p=2.91 \times 10^{-5}, d=0.60$, $95 \% \mathrm{CI}=[0.31,0.88])$ but not at low levels of participation $(1 S D$ below the mean; $b=0.02$, $S E=0.04, p=.64, d=0.07,95 \% \mathrm{CI}=[-0.21,0.35])$. In line with methodological recommendations (Garder et al., 2017), we also identified for each value of the moderator

\footnotetext{
${ }^{6}$ Given the significant correlation between the predictor variables, we checked for multicollinearity by investigating variance inflation factors (VIFs). The largest VIF value was 1.15 , which is much smaller than the rule-of-thumb cut-off point of 10 (Ryan, 1997).
} 
whether the predictor significantly predicted the criterion (Preacher, Curran \& Bauer, 2006; see also Johnson-Neyman, 1936). We found a positive significant relationship between teacher perceptions of principal trustworthiness (predictor) and student perception of teacher trustworthiness (criterion) for participation values higher than 4.22 (see Figure 3).

We then proceeded to test the next step of our mediation model. The results showed that student perception of teacher trustworthiness was positively related to student academic performance, $b=1.52, S E=0.38, p=5.98 \times 10^{-05}, d=0.57,95 \% \mathrm{CI}=[0.29,0.86]$.

Hypothesis 5 implies that teacher perception of principal trustworthiness predicts student perception of teacher trustworthiness, which in turn predicts student academic performance. This hypothesis further implies that participation moderates this indirect effect. As a formal test of our model, we assessed whether the index of moderated mediation differed from 0 (Hayes, 2015). If this index significantly differed from 0 , then it means that the indirect effect differed linearly across levels of the moderator. Our analyses revealed a significant index of moderated mediation $($ index $=0.11,95 \%$ quasi-Bayesian $\mathrm{CI}=[0.04$, 0.19]). ${ }^{7}$ Furthermore, we found a significant indirect relationship between teacher perceptions of principal trustworthiness and student academic performance, via student perception of teacher trustworthiness (indirect effect $=0.37,95 \% \mathrm{CI}=[0.14,0.64]$ ) at high but not at low levels of participation (indirect effect $=0.03,95 \% \mathrm{CI}=[-0.10,0.18]$ ). Thus, our results support Hypothesis $5 .^{8}$

\section{Discussion of Study 1 and Introduction to Study 2}

The findings of Study 1 support Hypothesis 5. Specifically, our results showed that supervisor (i.e., teacher) perceptions of manager (i.e., principal) trustworthiness predicted

\footnotetext{
${ }^{7}$ All 95\% bias corrected confidence intervals reported in this manuscript were based on 5000 resamples (see Preacher \& Hayes, 2004).

${ }^{8} \mathrm{We}$ also used alternative estimation techniques to check the robustness of our findings (Meyer et al., 2017). Our data are nested, and another way to take this data structure into account is by using hierarchical linear modeling (HLM) approach. All our findings are replicated in a HLM, and none of the fixed effects varied across groups.
} 
subordinate (i.e., student) perceptions of supervisor trustworthiness and-via the mediator of subordinate perception of supervisor trustworthiness - subordinate performance (i.e., student exam result). As predicted, this trickle-down effect of trustworthiness emerged only when the supervisor participated in managerial decision-making.

However, Study 1 also had limitations. One is that we cannot establish causality, because all the variables, except for the outcome variable, were measured at the same point in time. It is possible, for example, that trustworthiness perceptions do not trickle down to influence performance, but that high subordinate performance leads to higher perceived trustworthiness at higher hierarchical levels. In addition, higher order (i.e., third) variables may influence trustworthiness perceptions at various levels in the organization and subordinate performance.

A second limitation of Study 1 was that we did not test the specific theorized mechanism that explained why supervisor perception of manager trustworthiness would lead to subordinate perception of supervisor trustworthiness. In other words, we did not test the variable that we proposed linked these two perceptions, i.e., the trust behavior of the supervisor toward the subordinate.

To address these limitations, we conducted an experiment (Studies $2 \mathrm{a}$ and $2 \mathrm{~b}$ ) in which we tested Hypotheses 1 and 3 and at the same time assessed the causal direction of our proposed effects. We employed a yoked study design; we paired participants in the supervisor position with participants in the subordinate position (see also Anicich et al, 2015). This design allows testing of how behaviors of one person (i.e., participants in the supervisor position) affect the perceptions of another person (i.e., participants in the subordinate position). Specifically, our goals were to provide causal chain evidence that (1) supervisors will display behavior by which they make themselves more vulnerable to the subordinate when they perceive the manager as trustworthy and they are at the same time allowed to 
participate in the manager's decisions (Study 2a; test of Hypothesis 2); and that (2) the display of more trusting behavior by the supervisor should then be responded to positively by subordinates who perceive the supervisor as more trustworthy (Study 2b; test of Hypothesis 4).

\section{Method}

Sample and procedure. The participants, who were undergraduate business school students at a Dutch university, voluntary participated in exchange for course credit. In the first part of our yoked design (Study 2a), we assigned 202 participants to the supervisor position. We excluded 21 participants from analyses because they failed the attention check; this resulted in a final sample of 181 participants. On average, participants in the supervisor position were 19.88 years old $(S D=1.37)$. This sample consisted of 103 women and 78 men.

In the second part of our yoked design (Study 2b), we matched each participant from Study 2 a (i.e., a supervisor) with a participant in the subordinate position. We followed the same procedure as in Study 2a and invited 181 undergraduate students to participate. In line with Anicich et al. (2015), we also included an attention check in Study 2b. Because 33 participants failed the attention check and this design required that each supervisor matched with a unique subordinate, we invited 33 additional students to participate in Study $2 \mathrm{~b}$. This procedure resulted in a final sample of 181 participants who all passed the attention check and were matched with a unique supervisor. Participants in the subordinate position were on average 20.15 years old $(S D=2.18)$. This sample consisted of 75 men and 106 women.

Study 2a: trustworthiness and participation manipulation. In Study 2a, we assigned our participants randomly to one of four conditions in a 2 (Perceived Manager Trustworthiness: high vs. low) $\times 2$ (Participation: high vs. low) design.

Participants were invited to the laboratory where the experimenter greeted and escorted them to their cubicles. They then logged on to a computer and answered a trust scale 
(based on Yamagishi \& Yamagishi, 1994) that we also used at a later stage of the experiment to introduce the trustworthiness manipulation.

The participants were then led to believe that they would be participating in a group task with four other participants. To create a task-related context, we employed an in-basket task. This type of managerial role-playing exercise provides realism and external validity in studying organizational behavior while maintaining the advantages of doing research in a controlled environment (Treviño, 1992; Zedeck, 1986). Specifically, we told participants that they would be working in a simulated company that was hierarchically structured into three organizational levels, and we showed on the computer screen a visual illustration of the hierarchy. We told the participants that one group member would be placed at the manager position, another in the supervisor position, and three other members in the subordinate position. Subsequently, we indicated that a network connection would be established between them and the other team members. The participants then saw a screen that visually illustrated, by means of a line of running dots, that the server was connecting the participating individuals (see Appendix A for an illustration). This hierarchical setting was taken from van Dijke, De Cremer, Langendijk, and Anderson (2018).

Once the network connection was established, participants were informed about the position they would be taking in the organizational hierarchy. Unbeknownst to them, all participants were assigned to the supervisor position. They were then informed that the manager would contact them soon with further instructions. While they were waiting, we manipulated the trustworthiness of the manager. Specifically, we explained that the survey they all took part in at the start of the study was a scientifically proven instrument that measures the extent to which a person should be trusted or not. They were further told that based on this survey, participants would now be presented with data that would illustrate how much their manager could be trusted. In reality, these data were preprogrammed. The 
participants were then presented with a graph and a thorough explanation that, relative to an average person taking part in these studies, their manager could be trusted $(n=89)$ or could not be trusted $(\mathrm{n}=92)$. To ensure that the manipulation was interpreted correctly and enhanced the accessibility of high or low trust (see e.g., Galinksy, Gruenfeld, \& Magee, 2003 for the usefulness of accessibility techniques), we asked the participants to describe how a relationship with someone they perceived as trustworthy (vs. not trustworthy) feels and looks like. To test whether this manipulation was successful, we asked participants to rate the trustworthiness of their manager using the Brockner et al. scale $(1997 ; \alpha=.96)$.

After the trustworthiness manipulation, participants received an email with instructions from the manager. In reality, this information was preprogrammed and constituted our participation manipulation. The introduction to the manipulation read:

Hi there! As you know I am the senior manager in this organization and my job consists of making decisions that involve the entire organization. An important decision that I have to make involves streamlining our production line. These decisions always involve redefining the projects of the different departments and adjusting the job content of people at different positions within the company. These changes obviously have an influence on how we perform as a company and on our financial interests.

In the high participation condition $(\mathrm{n}=95)$, the message continued as follows:

I strongly believe in the art of participation, and therefore I want to involve you in many of these decisions. Specifically, I want to ask your opinion regularly on matters that require urgent and visionary decision-making, and I will begin doing this in a moment.

In the low participation condition $(n=86)$, the message continued as follows:

I do not believe in the art of participation and therefore I feel that everyone should stick to their tasks. As such, I do not intend to involve you in the decisions I have to make. Specifically, I will not ask your opinion on matters that require urgent and visionary decision-making.

To check whether the participation manipulation was successful, participants filled out the same 3-item IBQ participation subscale (Yukl \& Seifert, 2002; Cronbach's $\alpha=.92$ ) used in Study 1. After they received the message from their manager, we explained the next 
part of the study. The participants read that they would interact with their subordinates and that they would have to manage and supervise three tasks. Because they were appointed to the supervisor position, they had to be clear on how to approach their subordinates (i.e., trust behavior). For this reason, they were given the option to indicate how vulnerable they wanted to be towards their subordinates while they were working on these tasks. Specifically, they were asked to indicate the extent to which they wanted to monitor and have control over the outcome and decisions that their subordinates would be making during the three tasks (rather than leaving themselves vulnerable to the discretion of the subordinate). The scale ranged from 1 (not at all; no control) to 7 (totally; full control). We reverse-scored this scale when running the analyses. The less the participants wanted to monitor and control, the more vulnerable they made themselves to the actions of the subordinate. After responding to this question, the experiment was interrupted, ostensibly due to an error in the established connection with the other organizational members.

Next, participants were redirected to a question that served as an attention check: they were required to choose the second option from the left rather than answering the question (i.e., "Who is your favorite classical music composer?"; Oppenheimer, Meyvis, \& Davidenko, 2009). Finally, participants provided demographics, indicated their impressions of the experiment, and were thanked for their efforts.

Study $2 \mathbf{b}$. The participants in Study $2 \mathrm{~b}$ were randomly assigned to receive one specific response on the trust behavior measure provided by a participant from Study $2 \mathrm{a}$. Study $2 \mathrm{~b}$ was again conducted in the laboratory, and we used the same procedure as in Study 2a, except this time the participants were assigned to the subordinate level. They were informed that the supervisor would contact them soon to discuss the tasks that they and their colleagues would engage in. Before the participants started with their task, they were provided information about the extent to which their supervisor wanted to control their 
decisions during the task. This was done by giving them the score that their supervisor indicated on a scale from 1 to 7 , with a clear description of how the scale anchor points should be interpreted. After reading this, we asked the participants to rate the trustworthiness of their supervisor, again by using the Brockner et al. (1997) scale (Cronbach's $\alpha=.83$ ). As in Study 2a, after responding to these questions, the experiment was interrupted (allegedly by an error in the established connection with the other participants), and the participants were redirected to the final part of the study. There, they answered the same attention check as in Study 2a. Finally, they provided demographics and were thanked for their efforts.

\section{Results and Discussion}

Table 3 shows all means, standard deviations, and intercorrelations.

Study 2a manipulation checks. A one-way ANOVA with the manipulated perceived manager trustworthiness as independent variable and supervisor perception of manager trustworthiness as dependent variable revealed a significant main effect of perceived manager trustworthiness $\left(F(1,179)=275.44, p=4.66 \times 10^{-38}, d=2.47,95 \% \mathrm{CI}=[2.08,2.85]\right)$. Participants in the high trustworthiness condition considered their manager to be more trustworthy than the participants in the low-trustworthiness condition did (Ms = 5.38 vs. 2.63; SEs $=0.12$ vs. 0.12 , respectively).$^{9}$

A Perceived Manager Trustworthiness $\times$ Participation ANOVA on the participation manipulation check revealed a main effect of participation $\left(F(1,177)=522.55, p=1.05 \times 10^{-}\right.$ $\left.{ }^{54}, d=3.40,95 \% \mathrm{CI}=[2.95,3.86]\right)$. Compared to participants in the low-participation condition, those in the high participation condition felt that they were invited more to participate in decision-making $(M \mathrm{~s}=1.63$ vs. $4.84, S E \mathrm{~s}=0.10$ vs. 0.10 , respectively). The analysis did not reveal a significant main effect of perceived manager's trustworthiness $(F(1$,

\footnotetext{
${ }^{9}$ We report the estimated marginal means (EMM; sometimes called the least square means) throughout this manuscript because EMM take the influence of the covariates into account when reporting the mean of the dependent variable for each level of the factor (Lane \& Sandor, 2009). When there are no covariates in the model, the EMM is exactly the same as the mean.
} 
$177)=2.01, p=.16, d=0.21,95 \% \mathrm{CI}=[-0.08,0.50])$ or a Perceived Manager

Trustworthiness $\times$ Participation interaction $(F(1,177)=0.81, p=.37, d=0.13,95 \% \mathrm{CI}=[-$ $0.16,0.43])$.

Hypothesis testing. In this study, we tested whether perceived manager trustworthiness influences a supervisor trust behavior toward his/her subordinate and whether this effect is more pronounced at high (vs. low) levels of participation (Hypothesis 2). We also tested whether there was an indirect effect of supervisor perceived manager trustworthiness on subordinate perceived supervisor trustworthiness via supervisor trust behavior and whether this indirect effect was stronger when supervisors were invited to participate in managerial decision-making processes (Hypothesis 4; see Figure 1). We used ANOVA to test the direct effect of the Perceived Manager Trustworthiness $\times$ Participation interaction on supervisor trust behavior toward his/her subordinate. Then, we used OLS regression analysis to test for the direct effect of supervisor trust behavior on the extent to which the subordinate perceived his/her supervisor to be trustworthy. To analyze our proposed moderated mediation model, we followed the steps outlined by Kenny, Kashy, and Bolger (1998) by focusing on the paths that constituted the mediated effect. Then we calculated a $95 \%$ bootstrapped confidence interval to test the significance of the indirect effect. To assess the magnitude and overall significance of our model, we calculated an index of moderated mediation (Hayes, 2015). ${ }^{10}$

A 2 (Perceived Manager Trustworthiness) $\times 2$ (Participation) ANOVA on supervisor trust behavior did not reveal a significant main effect of perceived manager trustworthiness $(F(1,177)=0.23 p=.64, d=0.07,95 \% \mathrm{CI}=[-0.22,0.36])$. Analyses revealed a main effect of participation $(F(1,177)=6.26, p=.013, d=0.37,95 \% \mathrm{CI}=[0.08,0.67])$. This implies

\footnotetext{
${ }^{10}$ When the moderator is dichotomous (which was the case in the present study), the index of moderated mediation is a test of equality of the conditional indirect effects (Hayes, 2015).
} 
that when the manager invited the supervisor to participate, the supervisor was willing to be more vulnerable towards his/her subordinate than when he/she was not invited to participate $(M \mathrm{~s}=4.10$ vs. $3.68, S E \mathrm{~s}=0.12$ vs. 0.12 , respectively $)$.

The analysis also revealed a significant Perceived Manager Trustworthiness $\times$ Participation interaction $(F(1,177)=3.95, p=.05, d=0.30,95 \% \mathrm{CI}=[0.003,0.59]$; see Figure 4). Simple effects tests revealed that the positive effect of perceived manager trustworthiness on supervisor trust behavior (i.e. higher supervisor trust behavior when the supervisor perceived the manager as high versus low in trustworthiness) was more pronounced when the manager invited the supervisor to participate in decision-making $(M \mathrm{~s}=$ 4.31 vs. $3.89, S E \mathrm{~s}=0.16$ vs. 0.17 , respectively; $F(1,177)=3.39, p=.07, d=0.27,95 \% \mathrm{CI}=$ $[-0.02,0.57])$ than when the manager did not invite the supervisor to participate $(F(1,177)=$ $0.83, p=.36, d=0.14,95 \% \mathrm{CI}=[-0.16,0.42])$. This result supports Hypothesis 2.

We then proceeded to test the next part of our moderated mediation model: i.e., whether supervisor trust behavior affects the extent to which a subordinate perceives his/her supervisor to be trustworthy. An OLS regression analysis, in which we also included perceived manager trustworthiness, participation, and the Perceived Manager Trustworthiness $\times$ Participation interaction in our model, revealed that supervisor trust behavior increases the extent to which the subordinate perceives his/her supervisor to be trustworthy $(b=0.21, S E=$ $0.07, t=3.18, p=.002, d=0.47,95 \% \mathrm{CI}=[0.18,0.78])$.

As a final step, we tested the fuller moderated mediation model (see Figure 1). This necessitated testing whether the (manipulated) extent to which the manager was perceived as trustworthy predicts the extent to which the subordinate perceives his/her supervisor as trustworthy, via supervisor trust behavior, particularly when the manager invites the supervisor to participate in decision-making. We used Hayes' PROCESS macro (Hayes, 2013). The index of moderated mediation was significant (index $=0.14,95 \%$ bootstrapped CI 
$[0.015,0.391])$, which indicated that the indirect effect differed between high and low participation. More precisely, the relationship between the (manipulated) extent to which the supervisor perceived his/her manager to be trustworthy influenced subordinate perception of supervisor trustworthiness, via supervisor trust behavior, but only when supervisors were invited to participate by their manager (indirect effect $=0.09,95 \%$ bootstrapped CI $[0.004$, 0.272]). In contrast, when supervisors were not invited to participate by their managers, results did not show an indirect effect of manager trustworthiness via supervisor trust behavior (indirect effect $=-0.05,95 \%$ bootstrapped CI $[-0.187,0.036]$ ). These results support Hypothesis 4.

\section{Discussion of Study 2 and Introduction to Study 3}

In a controlled experimental setting, Study 2 provides causal evidence in support of Hypotheses 1 and 3. Specifically, our findings show that when supervisors perceived their manager to be trustworthy (vs. not trustworthy), they were more likely to show trusting behavior toward their subordinate, but only when they (the supervisor) participated in managerial decision-making. Furthermore, supervisor perceptions of manager trustworthiness indirectly influenced subordinate perceptions of supervisor trustworthiness, via the trust behavior that the supervisor displayed (when the supervisor was invited to participate in managerial decision making). This study thus provides causal evidence demonstrating when trustworthiness trickles down the organizational hierarchy, and it identifies supervisor trust behavior as a mechanism underlying this trickle-down effect.

Study 2 does suffer from some limitations, which we aim to remedy in Study 3. A first limitation is that we did not test why the interactive effect of supervisor perceptions of manager trustworthiness and participation in managerial decision-making influence supervisor trust behavior. We reasoned that the manager's decision to invite the supervisor to participate in decision-making would reinforce the manager becoming a role model for the 
supervisor to act in trusting ways toward others. This would suggest that social learning processes should be the mechanism by which the interactive effect influences supervisor trust behavior. To test for the role of social learning processes, we conducted Study 3. We used the same experimental manipulations and yoked design as in Study 2. We measured and tested social learning processes to assess their mediating role. We also measured and tested social exchange processes, as Wo et al. (2015) revealed evidence for social exchange but not for social learning processes. Scholars have argued that trust and justice are closely related concepts that reveal similar outcomes (Colquitt et al., 2013). It is therefore necessary to account for social exchange processes when testing our social learning hypothesis.

A second limitation is that in Study 2 participants were only offered information concerning the trustworthiness of their manager and not any other information on dimensions that are considered relevant to the managerial role. Such a trustworthiness manipulation can be regarded as heavy-handed and may therefore invite concerns about demand characteristics. To remove this concern, in Study 3 we again presented participants information about the trustworthiness of their manager but also presented additional information on other relevant managerial dimensions. As such, participants were not exposed to trustworthiness information only.

A final limitation of Study 2 was that we did not assess the performance of the participant occupying the subordinate role in Study $2 \mathrm{~b}$. As our theoretical model predicts a trickle-down process ultimately affecting the performance of the subordinate, we measured the performance of the subordinate in Study 3.

\section{Study 3}

\section{Method}

Sample and procedure. For study 3a, we recruited 200 working adults living in the United Kingdom through Prolific Academic (http://www.prolific.ac), an online platform that 
is explicitly designed for online participant recruitment by the scientific community (Palan \& Schitter, in press). Recent research provides evidence that the platform allows for gathering at least equally high quality data as the traditional University laboratory context (as in our Study 2) and higher quality data than alternative online platforms (Kappes, Balcetis, \& De Cremer, in press; Peer, Brandimarte, Samat, \& Acquisti, 2017). In the first part of this yoked design study (Study 3a), we assigned participants to the supervisor position. We excluded a total of 40 participants from our analyses because they failed on one or both of the two quality checks explained below. Our final sample consisted of 160 working adults, of which 34 were men. On average, the participants were 36.93 years old $(S D=9.79)$, had 17.45 years $(S D=9.41)$ of work experience, and worked 32.11 hours $(S D=11.50)$ per week.

We matched each participant (i.e., supervisor) in Study 3a with another participant (i.e., subordinate) from the subsequent Study 3b. Adopting the same procedure as in Study 3a, for Study $3 b$ we invited another 160 working adults to participate in our second study. In Study $3 \mathrm{~b}$ we also included an attention check that 24 participants failed to answer correctly. Therefore, because our design requires yoking each supervisor with a subordinate, we invited 24 additional working adults to participate in Study $3 b$. This resulted in a final sample of 160 unique supervisor-subordinate pairs who all answered the attention check correctly. On average, the participants in the subordinate position were 38.81 years old $(S D=10.46)$, worked 31.18 hours per week $(S D=10.87)$, and had 17.74 years $(S D=10.03)$ of work experience. The subordinate sample contained 52 men.

Study 3a: trustworthiness and participation manipulation. As in Study 2a, we assigned our participants randomly to one of four conditions in a 2 (Perceived Manager Trustworthiness: high vs. low) $\times 2$ (Participation: high vs. low) design. We used the same procedure and in-basket task as in Study 2 ( $a$ and b). Again, participants were presented with a screen that visually illustrated that they were, at the same time, connected with the other 
participating individuals. We also asked participants to indicate whether they agreed they were connected or not with other real participants. Thirty-three participants, or $16.5 \%$, did not believe this to be true, and were therefore excluded from further analyses. Regarding the perceived manager trustworthiness manipulation, we explained that the survey they all took part in at the start of the study was a scientifically proven instrument that measures several dimensions relevant to their job position in the organization. Based on this survey, participants were then presented with data illustrating the scores of their manager on four dimensions, with one of the dimensions reflecting the trustworthiness score of their manager. The other three dimensions were openness, administrative skills, and conceptual skills. We randomized the order in which we offered the information on each of these four dimensions to the participants across our experimental conditions. Order of offering the information did not influence the results in any of the analyses. As in Study 2, these data were preprogrammed and participants were told that their manager could either be trusted $(n=79)$ or not $(\mathrm{n}=81)$.

Subsequently, participants described how a relationship with someone they perceived as trustworthy (vs. not trustworthy) feels and looks like, as in Study 2a. To test whether this manipulation was successful, we asked participants to rate the extent to which they trust their manager, again using the Brockner et al. trustworthiness scale (1997; Cronbach's $\alpha=.99$ ). Regarding the participation manipulation, like in Study 2a, the participants received a message that their manager planned to either involve them in decisions $(n=88)$ or not $(n=$ 72). To check whether this manipulation was successful, participants responded to the same 3-item measure from the IBQ (Yukl \& Seifert, 2002; Cronbach's $\alpha=.91$ ) used in Study 2a.

Subsequently, the participants read that they would have to supervise three tasks and interact with their subordinates. As in Study 2a, we assessed the trust behavior of the participants (allocated to the supervisor condition). In Study 2, we used a measure of the first 
of the two primary components of trust: the intention to be vulnerable to subordinates (see Colquitt et al., 2007; Rousseau et al., 1998). In Study 3, we used a measure of the second dimension included in our trust definition: the expression of a positive expectation that the other party can be considered trustworthy (Colquitt et al., 2007; cf. Burt \& Knetz, 1996). Specifically, we asked participants to indicate the extent to which they considered as trustworthy the individuals (subordinates) they were to work with on the three tasks (see also the recommendation of Meyer et al. (2017) to use a different operationalization of the construct under investigation). The scale ranged from 1 (not at all) to 7 (very much so).

We also measured social learning and social exchange processes. We measured social learning with a 3-item scale taken from Wo et al. (2015; cf. Rich, 1997; Cronbach's $\alpha=.98$ ). We adjusted the scale to the context of our experimental setting. The items are: My manager "provides a good model for me to follow", "exhibits the kind of work ethic and behavior that I try to imitate." and "acts as a role model to me". We used the "felt obligation towards supervisors' scale", as an indicator of social exchange by adopting the 3 -item measure developed by Eisenberger, Armeli, Rexwinkel, Lynch, \& Rhoades (2001; Cronbach's $\alpha=$ .92). We adjusted the scale to the context of our experimental setting. The items are: "I feel a personal obligation to do whatever I can to help my senior manager achieve her/his goals.", "I owe it to my senior manager to give $100 \%$ of my energy to the goals I have to achieve while I am at work.", and "I have an obligation to my senior manager to ensure that I produce high-quality work." After the participants had responded to the questions, the experiment was ostensibly interrupted due to an error, and participants then answered demographics and the same attention check as in Study 2. Seven participants failed the attention check and were excluded from our analyses.

Study 3b. We randomly assigned participants in Study $3 b$ to receive one specific response on the behavioral trust measure provided by a participant from Study 3a. Study $3 b$ 
was again run on Prolific, and the participants were assigned to the subordinate level (as in Study 2b). They were informed that the supervisor would contact them soon to discuss the tasks that they and their colleagues would engage in. As in Study 2b, we informed participants about their supervisor's score on the trust behavior item using the same communication procedure. Participants then responded to Brockner et al.'s (1997) trustworthiness scale (Cronbach's $\alpha=.97)$. Then, we introduced the performance measure (extra-role performance; taken from Van Dijke, Wildschut, Leunissen, \& Sedikides, 2015). We told participants that their supervisor was required to engage in a task that was uniquely allocated by the top management of the organization to the person at the middle-management level. In this task the supervisor was required to solve as many word puzzles as possible. As this task was part of the unique requirements (and responsibilities toward the organization) for those at the middle-management level, employees were not required to help their supervisor. However, if the employees wanted to, they could help their supervisor with this task and, in this manner, help further promote organizational interests. Participants then indicated whether they wanted to help their supervisor with this task or not (yes or no). The participants then proceeded to the next page, ostensibly to start the remainder of the experiment. At this point, the experiment was interrupted (allegedly due to an error in the established connection with the other participants), and the participants were redirected to the final part of the study. They then answered the same attention check as in Study 3a. Finally, they provided demographics and were thanked for their efforts.

\section{Results and Discussion}

Table 4 shows all means, standard deviations, and intercorrelations.

Study 3a manipulation checks. A one-way ANOVA with the manipulated perceived manager trustworthiness as independent variable and supervisor perception of manager trustworthiness as dependent variable revealed a significant main effect of perceived manager 
trustworthiness $\left(F(1,158)=657.99, p=3.31 \times 10^{-58}, d=4.01,95 \% \mathrm{CI}=[3.51,4.60]\right)$. Participants in the high trustworthiness condition considered their manager to be more trustworthy than the participants in the low trustworthiness condition $\operatorname{did}(M \mathrm{~s}=5.78$ vs. 2.10; SEs $=0.10$ vs. 0.10 , respectively)

A 2 (Perceived Manager Trustworthiness) $\times 2$ (Participation) ANOVA on the participation manipulation check revealed a main effect of the participation manipulation, $F(1,156)=272.14, p=5.03 \times 10^{-36}, d=2.66,95 \% \mathrm{CI}=[2.23,3.08]$. Compared to participants in the low-participation condition, those in the high participation condition felt they were able to participate more in decision-making ( $M \mathrm{~s}=1.40 \mathrm{vs} .4 .39, S E \mathrm{~s}=.14$ vs. 12 , respectively). The results did not reveal a main effect of perceived manager trustworthiness, $F(1,156)=$ $1.72, p=.19, d=0.21,95 \% \mathrm{CI}=[-0.10,0.52]$, nor a significant Perceived Manager Trustworthiness $\times$ Participation interaction, $F(1,156)=0.02, p=.91, d=0.02,95 \% \mathrm{CI}=[-$ $0.29,0.33]$

Hypothesis testing. In this study, we tested whether the proposed trickle-down process of perceived manager trustworthiness, via supervisor trust behavior, to subordinate perceptions of supervisor trustworthiness, runs through social learning. In addition, we tested if this indirect effect is more pronounced when the supervisor is involved in managerial decision-making than when the supervisor is not (see Figure 1).

As in Studies 1 and 2, we tested this moderated mediation model by focusing on the paths that constitute the mediated effect. Specifically, we first conducted a two-way ANOVA to test the Perceived Manager Trustworthiness $\times$ Participation interaction on the extent to which the supervisor is likely to learn from the manager (i.e., a social learning process). Then, we used OLS regression analyses to test whether social learning predicts supervisor trust behavior (while controlling for social exchange processes). ${ }^{11}$ Subsequently, we tested if

\footnotetext{
${ }^{11}$ Results for all analyses that included social exchange as a control variable remained unchanged when social exchange was not entered as control variable.
} 
supervisor trust behavior predicts subordinate perceptions of supervisor trustworthiness. To analyze our full moderated mediation model, we estimated the index of moderated mediation of each parallel pathway (social learning and social exchange) and then inspected the conditional indirect effects. We assessed the significance of the index and indirect effects by calculating a $95 \%$ bias corrected bootstrapped confidence interval.

First, a $2 \times 2$ ANOVA on social learning showed a significant main effect of perceived manager trustworthiness, $F(1,156)=101.59, p=1.03 \times 10^{-18}, d=1.60,95 \% \mathrm{CI}=$ $[1.24,1.96]$. Participants who perceived their manager to be trustworthy were more likely to learn from their manager than those who did not consider their manager to be trustworthy $(M \mathrm{~s}=4.22$ vs. $2.37, S E \mathrm{~s}=0.13$ vs. 0.13 , respectively $)$. Results also revealed a significant main effect of Participation $\left(F(1,156)=168.33, p=1.42 \times 10^{-26}, d=2.05,95 \% \mathrm{CI}=[1.67\right.$, 2.43]). Supervisors were more likely to learn from their manager when their manager invited them to participate than when they were not invited to participate $(M \mathrm{~s}=4.48$ vs. $2.10, S E \mathrm{~s}=$ 0.12 vs. 0.13 , respectively). More importantly, the analysis revealed a significant Perceived Manager Trustworthiness $\times$ Participation interaction $\left(F(1,156)=12.80, p=4.62 \times 10^{-4}, d=\right.$ $0.57,95 \% \mathrm{CI}=[0.25,0.88]$; see Figure 5). Supervisors were more likely to learn from their manager when they perceived their manager as someone who is trustworthy than when they did not. This effect was stronger when the manager invited the supervisor to participate $(M \mathrm{~s}=$ 5.74 vs. $3.23, S E \mathrm{~s}=0.16$ vs. 0.18 , respectively; $F(1,156)=127.62, p=1.36 \times 10^{-29}, d=1.79$, $95 \% \mathrm{CI}=[1.42,2.15])$, than when there was no such invitation $(M \mathrm{~s}=2.70$ vs. $1.51, S E \mathrm{~s}=$ 0.21 vs. 0.18 , respectively; $F(1,156)=13.79, p=2.04 \times 10^{-4}, d=0.59,95 \% \mathrm{CI}=[0.27$, 0.90]). This finding supports Hypothesis 1.

To test an alternative pathway, we ran a $2 \times 2$ ANOVA on Social Exchange. Similar to the ANOVA on Social Learning, results revealed main effects of Supervisor Perceived Manager Trustworthiness, $M_{\text {high vs. low }}=4.82$ vs. $4.01, S E_{\text {high vs. low }}=0.16$ vs. $0.16, F(1,156)=$ 
$11.72, p=7.88 \times 10^{-4}, d=0.54,95 \% \mathrm{CI}=[0.23,0.86]$, and Participation, $M_{\text {high vs. } \text { low }}=5.37$ vs. $3.515, S E_{\text {high }}$ s. low $=0.15$ vs. $0.17, F(1,156)=69.50, p=3.74 \times 10^{-14}, d=1.32,95 \% \mathrm{CI}=$ $[0.98,1.66]$. However, no significant interaction term on Social Exchange emerged, $F(1,156)$ $=0.23, p=0.63, d=0.08,95 \% \mathrm{CI}=[-0.23,0.39]$.

We then tested the next stage of our proposed moderated mediation model, focusing on whether social learning predicts supervisor trust behavior. We conducted an OLS regression analysis in which we controlled for predictors from the first stage of the model (i.e., perceived manager trustworthiness, participation, and the Perceived manager Trustworthiness $\times$ Participation interaction term) and for social exchange. The analysis revealed that social learning was positively related to supervisor trust behavior, $b=0.59, S E$ $=0.09, t=6.94, p=1.02 \times 10^{-10}, d=1.10,95 \% \mathrm{CI}=[0.76,1.43]$. Moreover, and in support of Hypothesis 3, results revealed that the indirect effect of perceived manager trustworthiness on supervisor trust behavior via social learning was more pronounced when the supervisor was invited (vs. not invited) to participate in managerial decision-making (index of moderated mediation $=0.83,95 \% \mathrm{CI}=[0.44,1.34])$. Specifically, the indirect effect was more pronounced at high levels of participation (indirect effect $=1.34,95 \% \mathrm{CI}=[0.89,1.88]$ ) than at low levels of participation (indirect effect $=0.51,95 \% \mathrm{CI}=[0.17,0.96]$ ). Social exchange was not significantly related to supervisor trust behavior, $b=0.13, S E=0.07, t=1.80, p=$ $.07, d=0.28,95 \% \mathrm{CI}=[-0.03,0.60]$.

We then tested the next path of our proposed moderated mediation model, focusing on whether supervisor trust behavior predicts subordinate perception of supervisor trustworthiness. Again, we conducted an OLS regression analysis in which we controlled for predictors from the earlier stages of the model (including social exchange). Results showed that supervisor trust behavior was significantly related to the subordinate perception of supervisor trustworthiness, $b=0.58, S E=0.09, t=6.55, p=8.30 \times 10^{-10}, d=1.04,95 \% \mathrm{CI}=$ 
$[0.71,1.37]$.

We then assessed the last stage of our model. We checked whether subordinate perception of supervisor trustworthiness predicts subordinate performance. Because our performance measure is a dichotomous variable, we ran a logistic regression where we also controlled for predictors from the earlier stages of our proposed model. Results revealed a significant main effect of Perceived Supervisor Trustworthiness on performance, $b=0.71, S E$ $=0.18, \mathrm{z}=3.84, p=1.22 \times 10^{-4}, \mathrm{OR}=2.03, d=0.64,95 \% \mathrm{CI}=[0.32,0.95]$. The odds of helping the supervisor were 2.03 times higher if Perceived Supervisor Trustworthiness increased by 1 .

As a full test of our proposed model (see Figure 1), we calculated the index of moderated mediation of our full model. As previously stated, if this index is significantly different from zero, then the indirect effect of supervisor perceptions of manager trustworthiness $\rightarrow$ Social learning $\rightarrow$ Supervisor trust behavior $\rightarrow$ Subordinate perceptions of supervisor trustworthiness $\rightarrow$ subordinate performance, is contingent upon Participation (see Figure 1). Results confirmed this model by revealing a significant index of moderated mediation, (index $=0.32,95 \%$ bootstrapped CI $[0.09,0.83]$ ). The proposed indirect effect was more pronounced when the supervisor was invited to participate in decision-making (indirect effect $=0.61,95 \%$ bootstrapped CI $[0.19,1.33]$ ), than when he/she was not (indirect effect $=0.29,95 \%$ bootstrapped CI $[0.08,0.73])$. The pathway via social exchange did not have a significant index of moderated mediation (index $=-0.01,95 \%$ bootstrapped CI $[-0.13$, 0.03]). Further, the difference between the two indices of moderated mediation of social learning and social exchange was significant (index $\operatorname{SLminusSE}=0.33,95 \%$ bootstrapped CI $[0.09,0.81])$. In sum, Study 3 shows support for the entire model depicted in Figure $1 .{ }^{12}$

\footnotetext{
${ }^{12}$ We conducted a replication of Study 3 that differed in two ways from Study 3. First, we measured social exchange with the organizational support scale of Eisenberger et al. (2002), which was also used in the Wo et al. (2015) paper that tested for mediators of trickle down effects. Second, we did not measure employee performance in this study. The results of this replication were almost identical to the results of Study 3 . The
} 


\section{Discussion of Study 3}

Study 3 aimed to provide supportive evidence for all our Hypotheses by demonstrating that social learning processes underlie the effect of the interaction between supervisor perceptions of manager trustworthiness and supervisor participation in managerial decision-making on supervisor trust behavior. Moreover, we also showed that supervisor trust behavior - as driven by social learning processes - predicted subordinate perceptions of supervisor trustworthiness and subordinate performance level.

These findings are important because they identify the specific process that drives our interaction effect on supervisor trust behavior towards subordinates. As noted earlier, to the best of our knowledge, the trickle-down literature has failed to empirically test the validity of the theoretical frameworks used to guide research questions and theory-driven models and hypotheses. The only exception so far has been Wo et al. (2015), who found evidence in favor of social exchange and displaced aggression processes but not of social learning processes. Thus, our research contributes to the literature by providing further processoriented evidence in the context of trickle-down effects and by being the first to provide empirical support in favor of the social learning framework. We will elaborate on these contributions in the next section.

\section{General Discussion}

Building on social learning theory, we theorized and tested when and why trustworthiness perceptions trickle down from supervisors to subordinates and whether these perceptions ultimately affect the performance of subordinates. Our findings across three

\footnotetext{
analysis revealed that social learning was positively related to supervisor trust behavior $(b=0.35, S E=0.16, t=$ $2.15, p=.03, d=0.38,95 \% \mathrm{CI}=[0.03,0.73])$, whereas social exchange was not significantly related to supervisors' trust behavior $(b=0.22, S E=0.18, t=1.23, p=.22, d=0.22,95 \% \mathrm{CI}=[-0.13,0.56])$. Results further showed that the index of moderated mediation was significant (index $=0.25,95 \%$ bootstrapped CI $[0.02$, $0.58])$. The indirect effect of supervisor perceived trustworthiness of the manager via social learning processes was more pronounced when supervisors were invited to participate in decision-making (indirect effect $=0.39$, $95 \%$ bootstrapped CI $[0.01,0.81]$ ) than when they were not (indirect effect $=0.13,95 \%$ bootstrapped CI $[0.01$, $0.34]$ ).
} 
studies provided support for our hypotheses.

First, employing a multisource design, Study 1 demonstrated that supervisor perceptions of manager trustworthiness predicted subordinate performance via the mediating mechanism of subordinate perceptions of supervisor trustworthiness, and this indirect relationship emerged only when the supervisor participated in managerial decision-making.

Employing an experimental yoked design, Study 2 demonstrated that the interactive effect between supervisor perception of manager trustworthiness and supervisor participation in managerial decision-making influenced the extent to which the supervisor showed trusting behavior toward the subordinate, which in turn influenced subordinate perception of supervisor trustworthiness.

Using the same yoked design, Study 3 showed that the interactive effect of supervisor perceptions of manager trustworthiness and supervisor participation in managerial decisionmaking influenced supervisor trust behavior toward the subordinate via social learning processes, and this trust behavior in turn influenced subordinate perceptions of supervisor trustworthiness and subordinate performance level. In the next section, we discuss these findings and their implications.

\section{Theoretical Implications}

Our studies make several theoretical contributions. One contribution comes from our systematic exploration of how and why trustworthiness perceptions trickle down to affect the performance of subordinates. Fulmer and Gelfand (2012) noted in their review that one important recommendation for future research was to examine how and when trust built at one level trickles down in organizations to trust in other referents. Following this review, De Jong, Kroon, and Schilke (in press) inferred from their analysis of trust research published in top-tier management journals that research aimed at examining and understanding the dynamic diffusion of trust across parties and different hierarchical levels is still lagging. 
Studies so far have primarily focused only on considering the impact of properties of single dyads (e.g. Jones \& Shah, 2016; Yakovelva et al., 2010), which did not account for trickledown dynamics among trust referents. Our present research addresses this call by examining dynamics of how trustworthiness perceptions expand trust from higher to lower organizational levels by joining very recent research that illustrates that interpersonal trust as emerging from trustworthiness perceptions - needs to be examined as a socially embedded phenomenon (Fulmer \& Ostroff, 2017; Gupta et al., 2016). Important to note is that, contrary to this recent research, we suggest that trustworthiness perceptions happen in the minds of separate individuals at different levels of the organization. For this reason, we adopted a trickle-down approach, a paradigm that has not been used yet to investigate these dynamics of trust development (see De Jong et al., in press).

In the context of this trickle-down paradigm, we adopted a social learning theory perspective to predict when trustworthiness perceptions trickle down and which processes underlie the effect of supervisor perceptions of manager trustworthiness on subordinate performance. We illustrated in two ways the important role that social learning processes play in the trickling down of trustworthiness perceptions. First, in line with social learning theory (Bandura, 1986), we reasoned that supervisors set out to learn from their relationship with their manager to infer how to behave in terms of trust building in the organization. Perceiving the manager as trustworthy created a learning experience when the manager displayed behavior that allowed for creating a trusting relationship between the manager and supervisor (i.e. reinforcement of learning, Bandura, 1972). Specifically, we argued that if the manager invites the supervisor to participate in decision-making then the positive expectation held by the supervisor would be met and create trust between the supervisor and manager. In turn, this creation of a trusting relationship should then teach the supervisor to create trusting relationships with his/her own subordinates. Study 2 indeed showed the influence of this 
interactive effect between supervisor perception of manager trustworthiness and the supervisor participation in managerial decision-making on the emergence of supervisor trust behavior toward his or her subordinate. A second important point that supports the role of social learning processes is the finding in Study 3 that, as predicted, social learning processes mediate this interactive effect on the supervisor's trust behavior.

The results of our studies validate social learning theory as an explanatory framework for predicting and explaining the trickle-down process of trustworthiness perceptions in organizations. This finding provides an interesting addition to the literature for a variety of reasons. First, although a vast amount of trickle-down studies employ social learning theory as their guiding framework (e.g., Ambrose et al., 2013; Mawritz et al., 2012; Mayer et al., 2009; Simons et al., 2007), there has been no empirical test of social learning (or other mediating processes) until Wo et al. (2015). These authors empirically validated the three most prominent theoretical frameworks used in the trickle-down literature (i.e., social exchange theory, social learning theory, and displaced aggression) as possibly underlying interpersonal and informational justice trickle-down effects. Wo and colleagues found that interpersonal justice trickled down via displaced aggression processes and informational justice trickled down via social exchange processes. They did not find social learning to provide a mediating mechanism by which either type of justice judgments trickled down.

The fact that our present studies provide evidence for social learning processes as a mediating mechanism for the trickling down of trust differentiates our conclusions from Wo et al.'s (2015). There are several interesting implications to this. First, many scholars tended to consider the concepts of trust and justice as interchangeable (e.g., De Cremer, 2004; Konovsky \& Pugh, 1994; Colquitt et al., 2013; Kernan \& Hanges, 2002; Organ \& Konovsky, 1989). Empirical research about trust and justice linked these two concepts to similar organizational outcomes (Colquitt \& Rodell, 2011) and to each other (Van den Bos, Wilke, 
Lind \& Vermunt, 1998; see Cohen-Charash \& Spector, 2001; Colquitt et al., 2001; Dirks \& Ferrin, 2002 for meta-analyses). These findings led Lewicki, Wiethoff, and Tomlinson (2005: p. 253) more than a decade ago to conclude that both theoretical and empirical work "clearly point [sic] to a strong relationship between trust and justice.”

However, our findings, in combination with Wo et al.'s (2015), underscore the importance of looking at trust and justice as unique concepts because they appear to trickle down via different processes. As noted, both concepts share some commonalities. However, when it comes to explaining their impact within and mobility through organizational settings, they may have to be explained differently (De Cremer \& Tyler, 2007; Holtz, 2013, 2015). This implies that it cannot be taken for granted that closely related organizational behavior variables will necessarily trickle down in similar ways and for similar reasons. Thus, studies should focus on which theoretical account best explains the trickling down of the specific concept under investigation (in our case: trust) rather than on which theoretical perspective best explains trickle-down effects in general (see Wo et al., 2015).

\section{Practical Implications}

Our findings have several practical implications. Given that trust is associated with a variety of outcomes that are considered important for the functioning of organizations (see e.g., Colquitt et al., 2007), it would be wise for organizations to design effective efforts for promoting perceptions of trustworthiness throughout the organization. Our present research shows that to ensure that trusting relationships develop, it is crucial that managers reinforce the positive expectations that come along with the trustworthiness perceptions of their supervisors. This is a rewarding act that will create a trust relationship between managers and supervisors, which in turn will motivate supervisors to show trust behavior towards their own subordinates, thus creating trust relationships with them. Hence, an important task for management is to develop and reward trusting relationships at the top of the organization; this 
will make trusting behavior the norm to be picked up by supervisors. This process will provide a necessary input to the development of trust across all levels within the organization and will ultimately influence the performance of the subordinates. This insight suggests that trust development and training programs should be targeted, first and foremost, at the top of the company rather than at lower-level employees. If organizations want to build work forces that operate on a foundation of trust, it is necessary to get managers involved and to train them to know when and how to reward supervisors' trust toward managers.

Unfortunately, organizations usually do not invest many company resources to train higher management to actively build trusting relationships with their lower-level employees. There are a variety of reasons why investing in developing the trust-building qualities of those at the top are not considered an important business strategy. Trust is often mistaken for compliance, and as a result, organizations usually reason that designing systems to monitor and reward/punish (in)appropriate behaviors should suffice. However, the existence of such systems may undermine the presence of high quality and trusting relationships (e.g., Mulder, van Dijk, De Cremer, \& Wilke, 2006). Furthermore, for many companies, the contemporary wisdom that what cannot be measured does not exist (McAfee \& Brynjolfsson, 2012) applies to the notion of trust. Indeed, many organizations consider trust to be a soft concept that is difficult to quantify, and thus, less attention is paid to it. Nevertheless, given that employees are influenced strongly by their day-to-day interactions with their supervisors, and those supervisors are influenced strongly by their interactions with their managers, it follows that trust training for higher-level management should not be considered a fuzzy cost but as an important investment to create joint value in the long term.

\section{Strengths, Limitations, and Suggestions for Future Research}

An important strength of our research comes from our multimethod approach to studying the trickle-down effects of trustworthiness perceptions. The field study (Study 1) 
provides highly ecologically valid evidence for the trickling down of trustworthiness perceptions within organizations and its impact on employee performance. However, the internal validity of this study is limited. In contrast, the experiments (Studies 2 and 3) provide evidence high in internal validity for the mediation processes by which trustworthiness perceptions trickle down, but they are limited in external validity. Combining the use of both methodologies makes up for the limitations associated with each, thus promoting the overall validity of our series of studies. Specifically, our approach fits well with recent methodological recommendations to use randomized experimental designs (Studies 2 and 3) for testing moderated mediation (Stone-Romero \& Rosopa, 2008), which is what our hypotheses put forward. Because our experiments used a yoked design, we allowed for temporal separation between the predictors, the mediating mechanism, and the dependent variable. This allowed us to make stronger conclusions about the causal direction of the effects. Further, because we randomly assigned participants to a condition, we reduced the influence of omitted variables (Shadish, Cook \& Campbell, 2002). As Stone-Romero and Rosopa (2008, p. 329) note, "the findings of research using randomized experimental designs afford the firmest basis for inferences about cause in mediation models."

In this manner, our research provides an important contribution to the trickle-down literature. Most trickle-down studies have relied on cross-sectional designs, which has made arriving at valid causal conclusions impossible. Some trickle-down effect studies separated in time the measurement of the predictor and criterion variables (e.g., Wo et al., 2015), and yet these studies still do not allow for causal conclusions to be drawn. We know of only one other trickle-down study that employed an experimental design (Dvir, Eden, Avolio, \& Shamir, 2002). This study found that compared to an eclectic leadership training of top management, a transformational leadership training of top management had a more positive impact on the development of their direct followers and on the performance of lower-ranked 
organization members. As noted earlier, in contrast to the Dvir et al. (2002) study, we used an experimental yoked design that enabled us to study real trickle-down effects in a controlled setting. Connecting hierarchical levels in an experimental setting via a yoked design represents a methodological innovation to this literature.

A limitation of our experimental yoked design is that it focuses on one specific relationship that the supervisor has with a subordinate, when in fact supervisors usually supervise teams composed of several individuals. Thus, our findings do not extend to the trust behavior that a supervisor shows to several members of the team. This is an interesting future research question. Another suggestion for future research involves combining the use of different trickle paradigms. Our studies and those of others (e.g., Fulmer \& Ostroff, 2017; Gupta et al., 2016) demonstrate that subordinate performance is influenced by trustworthiness perceptions that develop within hierarchical settings. An important question that emerges from this observation is how to determine whose trustworthiness perceptions (e.g., subordinate or supervisor) of which other party (e.g., supervisor or manager) will have the strongest impact on subordinate performance. Addressing this question necessitates studying trickle-up and trickle-down effects simultaneously. We wish to note that such research will have to avoid any confusion concerning the steps to be tested to be able to speak of a trickle effect, which include factors like the trickle effects representing assessments in the minds of separate individuals across different hierarchical levels. As noted in Footnote 1, the research by Fulmer and Ostroff (2017) does not reflect such steps, as advocated by the standard definition of a trickle process. Therefore, researchers need to ensure that future work involving both trickle-up and trickle-down trustworthiness perceptions does encompass the steps required to test trickle-down effects adequately.

A final suggestion for future research is the simultaneous testing of trickle-down effects with trust transferability effects. In our present research, we found evidence that subordinates 
perceive their supervisor as trustworthy because this supervisor acts in trusting ways toward them (as a function of the interactive effect between supervisor perceptions of manager trustworthiness and supervisor participation in managerial decision-making). However, other processes could be at play as well, and trust transfer may be one of them (Ferrin et al., 2006; McEvily, Perone, \& Zaheer, 2003). Specifically, the trust one has in one party can be used as the basis to trust another party, thus providing a foundation for trust to be transferred between individuals (Uzzi, 1996). Similarly, it could be the case that subordinates trust their supervisors because they trust the supervisor's manager, and this could present an additional explanation for how trust in management would result in increased subordinate performance.

\section{Concluding Remarks}

Employing a trickle-down model and building on social learning theory, our present research helps to understand how trust can be built and extended throughout the organization through trickle-down effects. We show that trustworthiness perceptions at higher levels of the organization can influence, via trust behavior of the supervisor, trustworthiness perceptions and performance of subordinates, particularly when management invites participation of the supervisor. We hope that future researchers will further examine trust as a socially embedded phenomenon in understanding how it can serve the organization's welfare and the subordinate's functioning. 


\section{References}

Aguinis, H., Edwards, J. R., \& Bradley, K. J. (2017). Improving our understanding of moderation and mediation in strategic management research. Organizational Research Methods, 20, 665-685.

Aiken, L. S., West, S. G., \& Reno, R. R. (1991). Multiple regression: Testing and interpreting interactions. Thousand Oaks, CA: Sage Publications.

Ambrose, M. L., Schminke, M., \& Mayer, D. M. (2013). Trickle-down effects of supervisor perceptions of interactional justice: A moderated mediation approach. Journal of Applied Psychology, 98, 678-689.

Anicich, E. M., Fast, N. J., Halevy, N., \& Galinsky, A. D. (2016). When the bases of social hierarchy collide: Power without status drives interpersonal conflict. Organization Science, 27, 123-140.

Arrow, K. (1974). The limits of organization. New York: Norton.

Bandura, A. (1972). Modeling theory: some traditions, trends, and disputes. In R. D. Parke (Ed.), Recent trends in social learning theory. New York, NY: Academic Press.

Bandura, A. (1977). Social learning theory. Englewood Cliffs, N.J.: Prentice-Hall.

Bandura, A. (1986). Social foundations of thought and action: A social cognitive theory. Englewood Cliffs, NJ: Prentice-Hall.

Barber B. (1983). The logic and limits of trust. New Brunswick, NJ: Rutgers University Press.

Barcikowski, R. S. (1981). Statistical power with group mean as the unit of analysis. Journal of Educational Statistics, 6, 267-285.

Bates, D., Maechler, M., Bolker, B., \& Walker, S. (2015). Fitting linear mixed-effects models using lme4. Journal of Statistical Software, 67, 1-48.

Bernardin, H.J., Richey, B.E., \& Castro, S.L. (2011). Mandatory and binding arbitration: 
Effects on employee attitudes and recruiting results. Human Resource Management, 50, 175-200.

Bies, R. J., \& Shapiro, D. L. (1988). Voice and justification: Their influence on procedural fairness judgments. Academy of Management Journal, 31, 676-685.

Boon S.D., \& Holmes, J.G. (1991). The dynamics of interpersonal trust: Resolving uncertainty in the face of risk. In R.A. Hinde \& J. Groebel (Eds.), Cooperation and prosocial behaviour (pp. 190-211). Cambridge, England: Cambridge University Press.

Bordia, P., Restubog, S. L. D., Bordia, S., \& Tang, R. L. (2010). Breach begets breach: Trickle-down effects of psychological contract breach on customer service. Journal of Management, 36, 1578-1607.

Brockner, J., Siegel, P. A., Daly, J. P., Tyler, T., \& Martin, C. (1997). When trust matters: The moderating effect of outcome favorability. Administrative Science Quarterly, 42, $558-583$.

Bryant, M., \& Stensaker, I. (2011). The competing roles of middle management: Negotiated order in the context of change. Journal of Change Management, 11, 353-373.

Burt, R. S., \& Knetz, M. (1995). Kinds of third-party effects on trust. Rationality and Society, 7, 255-292.

Busemeyer, J. R., \& Jones, L. E. (1983). Analysis of multiplicative combination rules when the causal variables are measured with error. Psychological Bulletin, 93, 549-562.

Cohen-Charash, Y., \& Spector, P. E. (2001). The role of justice in organizations: A metaanalysis. Organizational Behavior and Human Decision Processes, 86, 278-321.

Colquitt, J. A., \& Rodell, J. B. (2011). Justice, trust, and trustworthiness: A longitudinal analysis integrating three theoretical perspectives. Academy of Management Journal, 54, 1183-1206.

Colquitt, J. A., Conlon, D. E., Wesson, M. J., Porter, C. O., \& Ng, K. Y. (2001). Justice at the 
millennium: A meta-analytic review of 25 years of organizational justice research. Journal of Applied Psychology, 86, 425-445.

Colquitt, J. A., Scott, B. A., \& LePine, J. A. (2007). Trust, trustworthiness, and trust propensity: A meta-analytic test of their unique relationships with risk taking and job performance. Journal of Applied Psychology, 92, 909-927.

Colquitt, J. A., Scott, B. A., Rodell, J. B., Long, D. M., Zapata, C. P., Conlon, D. E., \& Wesson, M. J. (2013). Justice at the millennium, a decade later: A meta-analytic test of social exchange and affect-based perspectives. Journal of Applied Psychology, 98, 199236.

Cook, K. S., \& Hardin, R. (2001). Norms of cooperativeness and networks of trust. In M. Hechter \& K.-D. Opp (Eds.), Social norms (pp. 327-347). New York: Russell Sage Foundation.

Cook, J., \& Wall, T. (1980). New work attitude measures of trust, organizational commitment and personal need non-fulfilment. Journal of Occupational and Organizational Psychology, 53, 39-52.

De Cremer, D. (2004). The influence of accuracy as a function of leader's bias: The role of trustworthiness in the psychology of procedural justice. Personality and Social Psychology Bulletin, 30, 293-304.

De Cremer, D., \& Tyler, T. (2007). The effects of trust in authority and procedural fairness on cooperation. Journal of Applied Psychology, 92, 639-649.

De Jong, B. A., Kroon, D.P., \& Schilke, O. (in press). The future of organizational trust research: A content-analytical synthesis of scholarly recommendations and review of recent developments. In P. van Lange, B. Rockenbach, \& T. Yamagishi (Eds.), Trust in social dilemmas. NY: Oxford University Press.

Dirks, K. T. (2000). Trust in leadership and team performance: Evidence from NCAA 
basketball. Journal of Applied Psychology, 85, 1004-1012.

Dirks, K. T., \& Ferrin, D. L. (2001). The role of trust in organizational settings. Organization Science, 12, 450-467.

Dirks, K. T., \& Ferrin, D. L. (2002). Trust in leadership: Meta-analytic findings and implications for research and practice. Journal of Applied Psychology, 87, 611-628.

Dirks, K. T., \& Skarlicki, D. P. (2009). The relationship between being perceived as trustworthy by coworkers and individual performance. Journal of Management, 35, 136 $-157$.

Dvir, T., Eden, D., Avolio, B. J., \& Shamir, B. (2002). Impact of transformational leadership on follower development and performance: A field experiment. Academy of Management Journal, 45, $735-744$.

Earley, P. C. (1986). Trust, perceived importance of praise and criticism, and work performance: An examination of feedback in the United States and England. Journal of Management, 12, 457-473.

Eisenberger, R., Stinglhamber, F., Vandenberghe, C., Sucharski, I. L., \& Rhoades, L. (2002). Perceived supervisory support: Contributions to perceived organizational support and employee retention. Journal of Applied Psychology, 87, 565-573.

Erdogan, B., Liden, R. C., \& Kraimer, M. L. (2006). Justice and leader-member exchange: The moderating role of organizational culture. Academy of Management Journal, 49, $395-406$.

Ferrin, D.L., \& Dirks, K.T. (2003). The use of rewards to increase and decrease trust: Mediating processes and differential effects. Organization Science, 14, 18-31.

Ferrin, D. L., Dirks, K. T., \& Shah, P. P. (2006). Direct and indirect effects of third-party relationships on interpersonal trust. Journal of Applied Psychology, 91, 870 - 883.

Flores, F., \& Solomon, R. C. (1998). Creating trust. Business Ethics Quarterly, 8, 205-232. 
Folger, R. (1977). Distributive and procedural justice: Combined impact of "voice" and improvement of experienced inequality. Journal of Personality and Social Psychology, 35, 108-119.

Fulmer, C. A., \& Gelfand, M. J. (2012). At what level (and in whom) we trust: Trust across multiple organizational levels. Journal of Management, 38, 1167-1230.

Fulmer, C. A., \& Ostroff, C. (2017). Trust in direct leaders and top leaders: A trickle-up model. Journal of Applied Psychology, 102, 648-657.

Galinsky, A. D., Gruenfeld, D. H., \& Magee, J. C. (2003). From power to action. Journal of personality and social psychology, 85, 453-466.

Gardner, R. G., Harris, T. B., Li, N., Kirkman, B. L., \& Mathieu, J. E. (2017). Understanding "It Depends" in Organizational Research: A Theory-Based Taxonomy, Review, and Future Research Agenda Concerning Interactive and Quadratic Relationships. Organizational Research Methods, 20, 610-638.

Gelade, G. A., \& Ivery, M. (2003). The impact of human resource management and work climate on organizational performance. Personnel Psychology, 56, 383-404.

Gillespie, N., \& Mann, L. (2004). Transformational leadership and shared values: The building blocks of trust. Journal of Managerial Psychology, 19, 588-607.

Govier (1994). Is it a jungle out there? Trust, distrust and the construction of social reality. Dialogue: Canadian Philosophical Review, 33, 237-252.

Gupta, N., Ho, V., Pollack, J. M., \& Lai, L. (2016). A multilevel perspective of interpersonal trust: Individual, dyadic, and cross-level predictors of performance. Journal of Organizational Behavior, 37, 1271-1292.

Hayes, A. F. (2013). Introduction to mediation, moderation, and conditional process analysis: A regression-based approach. New York, NY: Guilford Press.

Hayes, A. F. (2015). An index and test of linear moderated mediation. Multivariate 
Behavioral Research, 50, 1-22.

Holmes, J. G. (1991). Trust and the appraisal process in close relationships. In W. H. Jones \& D. Perlman (Eds.), Advances in personal relationships, (Vol. 2, pp. 57-104). London: Jessica Kingsley.

Holtz, B. C. (2013). Trust primacy: A model of the reciprocal relations between trust and perceived justice. Journal of Management, 39, 1891-1923.

Holtz, B. C. (2015). From first impression to fairness perception: Investigating the impact of initial trustworthiness beliefs. Personnel Psychology, 68, 499-546.

Huang, X., Iun, J., Liu, A., \& Gong, Y. (2010). Does participative leadership enhance work performance by inducing empowerment or trust? The differential effects on managerial and non-managerial subordinates. Journal of Organizational Behavior, 31, 122-143.

Johnson, P. O., \& Neyman, J. (1936). Tests of certain linear hypotheses and their applications to some educational problems. Statistical Research Memoirs, 1, 57-93.

Jones, G.R., \& George, J.M. (1998). The experience and evolution of trust: Implications for cooperation and teamwork. Academy of Management Review, 23, 531-546.

Jones, S.L., \& Shah, P.P. (2016). Diagnosing the locus of trust: A temporal perspective for trustor, trustee, and dyadic influences on perceived trustworthiness. Journal of Applied Psychology, 101, 392-414.

Kenny, D. A., Kashy, D. A., \& Bolger, N. (1998). Data analysis in social psychology. The Handbook of Social Psychology, 1, 233-265.

Kernan, M. C., \& Hanges, P. J. (2002). Survivor reactions to reorganization: Antecedents and consequences of procedural, interpersonal, and informational justice. Journal of Applied Psychology, 87, 916-928.

Konovsky, M. A., \& Pugh, S. D. (1994). Citizenship behavior and social exchange. Academy of Management Journal, 37, 656-669. 
Korsgaard, M.A., Brodt, S.E., \& Whitener, E.M. (2002). Trust in the face of conflict: The role of managerial trustworthy behavior and organizational context. Journal of Applied Psychology, 87, 312-319.

Korsgaard, M.A., Brower, H.H., \& Lester, S.W. (2015). It isn't always mutual: A critical review of dyadic trust. Journal of Management, 41, 47-70.

Korsgaard, M. A., Schweiger, D. M., \& Sapienza, H. J. (1995). Building commitment, attachment, and trust in top management teams: The role of procedural justice. Academy of Management Journal, 38, 60-84.

Kosfeld, M., Heinrichs, M., Zak, P. J., Fischbacher, U., \& Fehr, E. (2005). Oxytocin increases trust in humans. Nature, 435, 673-676.

Kramer, R. M. (1996). Divergent realities and convergent disappointments in the hierarchic relation: Trust and the intuitive auditor at work. In R. M. Kramer \& T. R. Tyler (Eds.), Trust in organizations: Frontiers of theory and research (pp. 216-245). Thousand Oaks, CA: Sage.

Kramer, R. M. (1999). Trust and distrust in organizations: Emerging perspectives, enduring questions. Annual Review of Psychology, 50, 569-598.

Kramer, R. M., \& Isen, A. M. (1994). Trust and distrust: Its psychological and social dimensions. Motivation and emotion, 18, 105-107.

Lane, D. M., \& Sándor, A. (2009). Designing better graphs by including distributional information and integrating words, numbers, and images. Psychological Methods, 14, 239-257.

Lewicki, R., \& Bunker, B. (1996). Developing and maintaining trust in work relationships. In R. Kramer \& T.R. Tyler (Eds.), Trust in organizations: Frontiers of theory and research (pp. 114-139). Thousand Oaks, CA: Sage.

Lewicki, R. J., Tomlinson, E. C, \& Gillespie, N. (2006). Models of interpersonal trust 
development: Theoretical approaches, empirical evidence, and future directions. Journal of Management, 32, 991-1022.

Lewicki, R. J., Wiethoff, C., \& Tomlinson, E. C. (2005). What is the role of trust in organizational justice? In J. Greenberg \& J. A. Colquitt (Eds.), Handbook of organizational justice (pp. 247-270). Mahwah, NJ: Erlbaum.

Lewis, J.D., \& Weigert, A. (1985). Trust as a social reality. Social Forces, 63, 967-985.

Li, A. N. \& Tan, H. H. (2013). What happens when you trust your supervisor? Mediators of individual performance in trust relationships. Journal of Organizational Behavior, 34, 407-425.

MacKinnon, D. P. (2008). Introduction to statistical mediation analysis. New York: Lawrence Erlbaum Associates.

Masterson, S. S. (2001). A trickle-down model of organizational justice: Relating employees' and customers' perceptions of and reactions to fairness. Journal of Applied Psychology, 86, 594-604.

Mawritz, M. B., Mayer, D. M., Hoobler, J. M., Wayne, S. J., \& Marinova, S. V. (2012). A trickle-down model of abusive supervision. Personnel Psychology, 65, 325-357.

Mayer, D. M., Kuenzi, M., Greenbaum, R. L., Bardes, M., \& Salvador, R. (2009). How does ethical leadership flow? Test of a trickle-down model. Organizational Behavior and Human Decision Processes, 108, 1-13.

Mayer, R. C., \& Gavin, M. B. (2005). Trust in management and performance: who minds the shop while the employees watch the boss? Academy of Management Journal, 48, 874888.

Mayer, R. C., Davis, J. H., \& Schoorman, F. D. (1995). An integrative model of organizational trust. Academy of Management Review, 20, 709-734.

McAfee, A., \& Brynjolfsson, E. (2012). Big data: The management revolution. Harvard 
Business Review, October, 61-68.

McEvily, B., \& Tortoriello, M. (2011). Measuring trust in organisational research: Review and recommendations. Journal of Trust Research, 1, 23-63.

McEvily, B., Perrone, V., \& Zaheer, A. (2003). Trust as an organizing principle. Organization science, 14, 91-103.

McKnight, D. H., Cummings, L. L., \& Chervany, N. L. (1998). Initial trust formation in new organizational relationships. Academy of Management Review, 23, 473-490.

McNeish, D., Stapleton, L.M., \& Silverman, R.D. (2017). On the unnecessary ubiquity of hierarchical linear modeling. Psychological Methods, 22, 114-140.

Meade, A. W., \& Craig, S. B. (2012). Identifying careless responses in survey data. Psychological Methods, 17, 437-455.

Meyer, K. E., van Witteloostuijn, A., \& Beugelsdijk, S. (2017). What's in a p? Reassessing best practices for conducting and reporting hypothesis-testing research. Journal of International Business Studies, 48, 535-551.

Meyerson, D., Weick, K. E., \& Kramer, R. M. (1996). Swift trust and temporary groups. In R. M. Kramer \& T. R. Tyler (Eds.), Trust in organizations: Frontiers of theory and research, (pp. 166-195). California: Sage Publications, Inc.

Mulder, L. B., Van Dijk, E., De Cremer, D., \& Wilke, H. A. (2006). Undermining trust and cooperation: The paradox of sanctioning systems in social dilemmas. Journal of Experimental Social Psychology, 42, 147-162.

Muthén, L. K., \& Muthen, B. (2010). Mplus 6.0. Los Angeles, CA: Muthén \& Muthén.

Oppenheimer, D. M., Meyvis, T., \& Davidenko, N. (2009). Instructional manipulation checks: Detecting satisficing to increase statistical power. Journal of Experimental Social Psychology, 45, 867-872.

Organ, D. W., \& Konovsky, M. (1989). Cognitive versus affective determinants of 
organizational citizenship behavior. Journal of Applied Psychology, 74, 157-164.

Palanski, M. E., \& Yammarino, F. J. (2009). Integrity and leadership: A multi-level conceptual framework. The Leadership Quarterly, 20, 405-420.

Peer, E., Brandimarte, L., Samat, S., \& Acquisti, A. (2017). Beyond the Turk: Alternative platforms for crowdsourcing behavioral research. Journal of Experimental Social Psychology, 70, 153-163.

Podsakoff, N. P., Whiting, S. W., Podsakoff, P. M., \& Blume, B. D. (2009). Individual- and organizational-level consequences of organizational citizenship behaviors: A metaanalysis. Journal of Applied Psychology, 94, 122-141.

Preacher, K. J., \& Hayes, A. F. (2004). SPSS and SAS procedures for estimating indirect effects in simple mediation models. Behavior Research Methods, Instruments, \& Computers, 36, 717-731.

Preacher, K. J., Curran, P. J., \& Bauer, D. J. (2006). Computational tools for probing interaction effects in multiple linear regression, multi-level modeling, and latent curve analysis. Journal of Educational and Behavioral Statistics, 31, 437-448.

Raes, A. M., Heijltjes, M. G., Glunk, U., \& Roe, R. A. 2011. The interface of the top management team and middle managers: A process model. Academy of Management Review, 36: 102-126.

Read, W. H. (1962). Upward communication in industrial hierarchies. Human Relations, 15, 3-15.

Rempel, J. K., Holmes, J. G., \& Zanna, M. D. (1985). Trust in close relationships. Journal of Personality and Social Psychology, 49, 95-112.

Rich, G. A. (1997). The sales manager as a role model: Effects on trust, job satisfaction, and performance of salespeople. Journal of the Academy of Marketing Science, 25, 319-328. Roberts, K.H., \& O’ Reilly, C.A. (1974). Measuring organizational communication. Journal 
of Applied Psychology, 59, 321-326.

Ross, W., \& LaCroix, J. (1996). Multiple meanings of trust in negotiation theory and research: A literature review and integrative model. International Journal of Conflict Management, 7, 314-360.

Rotter, J. B. (1967). A new scale for the measurement of interpersonal trust. Journal of Personality, 35, 615-665.

Rotter, J. B. (1971). Generalized expectancies for interpersonal trust. American Psychologist, 26, 443-452.

Rousseau, D. M., Sitkin, S. B., Burt, R. S., \& Camerer, C. (1998). Not so different after all: A cross-discipline view of trust. Academy of Management Review, 23, 393-404.

Ryan, T. P. (1997). Modern regression methods. New York: Wiley.

Satorra, A., \& Bentler, P. M. (1988). Scaling corrections for chi-square statistics in covariance structure analysis. Proceedings of the American Statistical Association, 308313.

Schuh, S. C., Zhang, X., Egold, N. W., Graf, M. M., Pandey, D., \& van Dick, R. (2012). Leader and follower organizational identification: The mediating role of leader behavior and implications for follower OCB. Journal of Occupational and Organizational Psychology, 85, 421-432.

Shadish, W. R., Cook, T. D., \& Campbell, D. T. (2002). Experimental and quasiexperimental designs for generalized causal inference. Boston: Houghton Mifflin.

Shanock, L. R., \& Eisenberger, R. (2006). When supervisors feel supported: Relationships with subordinates' perceived supervisor support, perceived organizational support, and performance. Journal of Applied Psychology, 91, 689-695.

Simons, T. (2002). Behavioral integrity: The perceived alignment between managers' words and deeds as a research focus. Organization Science, 13, 18-35. 
Simons, T., Friedman, R., Liu, L. A., \& Parks, J. M. (2007). Racial differences in sensitivity to behavioral integrity: Attitudinal consequences, in-group effects, and "trickle-down" among black and non-black employees. Journal of Applied Psychology, 92, 650-665.

Sniezek, J. A., \& Van Swol, L. M. (2001). Trust, confidence, and expertise in a judge-advisor system. Organizational behavior and human decision processes, 84, 288-307.

Stone-Romero, E. F., \& Rosopa, P. J. (2008). The relative validity of inferences about mediation as a function of research design characteristics. Organizational Research Methods, 11, 326-352.

Tepper, B. J., \& Taylor, E. C. (2003). Relationships among supervisors' and subordinates' procedural justice perceptions and organizational citizenship behaviors. Academy of Management Journal, 46, 97-105.

Tingley, D., Yamamoto, T., Hirose, K., Keele, L., \& Imai, K. (2014). Mediation: R package for causal mediation analysis. Journal of Statistical Software, 59, 1-38.

Treviño, L. K. (1992). Experimental approaches to studying ethical/unethical behavior in organizations. Business Ethics Quarterly, 2, 121-136.

Uzzi, B. (1996). The sources and consequences of embeddedness for the economic performance of organizations: The network effect. American Sociological Review, 61, 674-698.

Van den Bos, K. (1999). What are we talking about when we talk about no-voice procedures? On the psychology of the fair outcome effect. Journal of Experimental Social Psychology, 35, $560-577$.

Van den Bos, K., Wilke, H. A. M., Lind, E. A., \& Vermunt, R. (1998). Evaluating outcomes by means of the fair process effect: Evidence for different processes in fairness and satisfaction judgments. Journal of Personality and Social Psychology, 74, 1493-1503.

Van Dijke, M.H., De Cremer, D., Langendijk, G., \& Anderson, C. (2018). Ranking low, 
feeling high: How hierarchical position and experienced power promote prosocial behavior in response to procedural justice. Journal of Applied Psychology, 103, 164-181.

Van Dijke, M.H., Wildschut, T., Leunissen, J. M., \& Sedikides, C. (2015). Nostalgia buffers the negative impact of low procedural justice on cooperation. Organizational Behavior and Human Decision Processes, 127, 15-29.

M. Williams (2001). In whom we trust: group membership as an affective context for trust development. Academy of Management Review, 26, 377-396.

Whitson, J., Wang, C. S., Kim, J., Cao, J., \& Scrimpshire, A. (2015). Responses to normative and norm-violating behavior: Culture, job mobility, and social inclusion and exclusion. Organizational Behavior and Human Decision Processes, 129, 24-35.

Wo, D. X., Ambrose, M. L., \& Schminke, M. (2015). What drives trickle-down effects? A test of multiple mediation processes. Academy of Management Journal, 58, 1848-1868.

Yakovleva, M., Reilly, R.R., \& Werko, R. (2010). Why do we trust? Moving beyond individual to dyadic perceptions. Journal of Applied Psychology, 95, 79-91.

Yamagishi, T., \& Yamagishi, M. (1994). Trust and commitment in the United States and Japan. Motivation and Emotion, 18, 129-166.

Yukl, G., \& Seifert, C. F. (2002). Preliminary validation research on the extended version of the influence behavior questionnaire. Paper presented at the annual conference of the Society for Industrial and Organizational Psychology.

Zand, D. E. (1972). Trust and managerial problem solving. Administrative Science Quarterly, 17, 229-239.

Zedeck, S. (1986). A process analysis of the assessment center method. Research in Organizational Behavior, 8, 259-296. 
Table 1.

Study 1: Means, standard deviations, and correlations

\begin{tabular}{|c|c|c|c|c|c|c|c|c|c|c|}
\hline Variable & $M$ & $S D$ & 1 & 2 & 3 & 4 & 5 & 6 & 7 & 8 \\
\hline 1. Gender Students & - & - & & & & & & & & \\
\hline 2. Age Students & 14.03 & 1.63 & .05 & & & & & & & \\
\hline 3. Gender Teachers & 1.72 & 0.45 & -.09 & $-.35^{* * *}$ & & & & & & \\
\hline 4. Age Teachers & 45.20 & 8.31 & .12 & $.26^{* * *}$ & $-.32 * * *$ & & & & & \\
\hline 5. Tenure Teachers & 18.11 & 9.00 & .12 & .01 & $-.34 * * *$ & $.68 * * *$ & & & & \\
\hline $\begin{array}{l}\text { 6. Teacher Perceived } \\
\text { Trustworthiness of Principal }\end{array}$ & 4.64 & 1.35 & -.10 & $-.46 * * *$ & .14 & -.07 & -.11 & & & \\
\hline $\begin{array}{l}\text { 7. Student Perceived } \\
\text { Trustworthiness of Teacher }\end{array}$ & 5.54 & 1.02 & .05 & $-.29 * * *$ & .07 & $-.20 * *$ & $-.19 * *$ & $.24 * * *$ & & \\
\hline 8. Participation & 4.86 & 1.57 & .05 & $-.51 * * *$ & .12 & -.11 & -.06 & $.36^{* *}$ & $.26 * * *$ & \\
\hline 9. Student Academic Performance & 65.53 & 9.07 & .03 & $-.20 * *$ & .12 & .00 & -.00 & $.14^{*}$ & $.19 * *$ & .07 \\
\hline
\end{tabular}

Note. Men are coded as 1; Women are coded as 2; * $p<.05$ (2-tailed), ** $p<.01$ (2-tailed), *** $p<.001$ (2-tailed); M and SD are used to represent mean and standard deviation, respectively. 
Table 2.

Results Study 1: Predicting Student Perceptions of Teacher Trustworthiness and Student Academic Performance

\begin{tabular}{|c|c|c|c|c|c|c|}
\hline \multirow[b]{2}{*}{ Predictor } & \multicolumn{3}{|c|}{$\begin{array}{c}\text { Criterion: Student Perceptions of Teacher } \\
\text { Trustworthiness }\end{array}$} & \multicolumn{3}{|c|}{ Criterion: Student Academic Performance } \\
\hline & $b(S E)$ & $t$ & Cohen's d [95\% CI] & $b(S E)$ & $t$ & Cohen's d [95\% CI] \\
\hline Intercept & $5.48(0.07)$ & 81.94 & $11.65[10.49,12.86]$ & $57.13(1.80)$ & 31.74 & $4.52[4.00,5.05]$ \\
\hline $\begin{array}{l}\text { Teacher Perceptions of Principal } \\
\text { Trustworthiness }\end{array}$ & $0.13(0.04)$ & 3.01 & $0.43[0.15,0.71]$ & $0.71(0.68)$ & 1.04 & $0.15[-0.13,0.42]$ \\
\hline Participation & $0.13(0.05)$ & 2.54 & $0.36[0.08,0.64]$ & $-0.10(0.62)$ & -0.17 & $-0.02[-0.30,0.26]$ \\
\hline $\begin{array}{l}\text { Teacher Perceptions of Principal } \\
\text { Trustworthiness } \times \text { Participation }\end{array}$ & $0.07(0.02)$ & 4.06 & $0.58[0.29,0.86]$ & $-0.06(0.24)$ & -0.23 & $-0.03[-0.31,0.25]$ \\
\hline $\begin{array}{l}\text { Student Perceptions of Teacher } \\
\text { Trustworthiness }\end{array}$ & & & & $1.52(0.38)$ & 4.01 & $0.57[0.29,0.86]$ \\
\hline $\mathrm{R}^{2}$ & .12 & & & .05 & & \\
\hline
\end{tabular}


Table 3.

Study 2: Means, standard deviations, and correlations

\begin{tabular}{|c|c|c|c|c|c|c|c|c|c|}
\hline Variable & $M$ & $S D$ & 1 & 2 & 3 & 4 & 5 & 6 & 7 \\
\hline 1. Supervisor Gender & - & - & & & & & & & \\
\hline 2. Supervisor Age & 19.88 & 1.37 & .02 & & & & & & \\
\hline 3. Employee Gender & - & - & -.03 & -.07 & & & & & \\
\hline 4. Employee Age & 20.15 & 2.18 & -.09 & .08 & -.01 & & & & \\
\hline $\begin{array}{l}\text { 5. Perceived Manager } \\
\text { Trustworthiness }\end{array}$ & 0.49 & 0.50 & .05 & .02 & -.09 & $.17^{*}$ & & & \\
\hline 6. Participation & 0.52 & 0.50 & -.02 & .07 & -.04 & .04 & .05 & & \\
\hline 7. Supervisor trust behavior & 3.91 & 1.15 & .13 & -.04 & -.03 & -.02 & .05 & $.18^{*}$ & \\
\hline $\begin{array}{l}\text { 8. Perceived Supervisor } \\
\text { trustworthiness }\end{array}$ & 4.42 & 1.00 & -.03 & -.05 & .13 & -.03 & -.03 & .11 & $.24 * * *$ \\
\hline
\end{tabular}

Note. $* p<.05$ (2-tailed), ** $p<.01$ (2-tailed), *** $p<.001$ (2-tailed) $M$ and SD are used to represent mean and standard deviation, respectively. Men are coded as 1; Women are coded as 2; Both Perceived manager trustworthiness and Participation were manipulated, where 1 and 0 indicate the high and low conditions respectively. 
Table 4

Study 3: Means, standard deviations, and correlations

\begin{tabular}{|c|c|c|c|c|c|c|c|c|c|c|c|c|}
\hline Variable & $M$ & $S D$ & 1 & 2 & 3 & 4 & 5 & 6 & 7 & 8 & 9 & 10 \\
\hline 1. Supervisor Gender & - & - & & & & & & & & & & \\
\hline 2. Supervisor Age & 36.93 & 9.79 & $-.16^{*}$ & & & & & & & & & \\
\hline 3. Employee Gender & - & - & -.00 & .04 & & & & & & & & \\
\hline 4. Employee Age & 38.81 & 10.46 & .04 & .07 & -.03 & & & & & & & \\
\hline $\begin{array}{l}\text { 5. Perceived Manager } \\
\text { Trustworthiness }\end{array}$ & 0.49 & 0.50 & -.04 & -.14 & -.09 & .03 & & & & & & \\
\hline 6. Participation & 0.55 & 0.50 & .02 & .00 & .04 & .11 & .14 & & & & & \\
\hline 7. Supervisor trust behavior & 3.94 & 1.82 & .02 & -.04 & -.01 & .06 & $.48 * * *$ & $.56 * * *$ & & & & \\
\hline 8. Felt Obligation & 4.52 & 1.74 & .04 & .06 & .00 & .15 & $.29 * * *$ & $.57 * * *$ & $.62 * * *$ & & & \\
\hline 9. Social Learning & 3.45 & 2.00 & .00 & -.08 & -.05 & .09 & $.56 * * *$ & $.65^{* * * *}$ & $.79 * * *$ & $.68 * * *$ & & \\
\hline $\begin{array}{l}\text { 10. Perceived Supervisor } \\
\text { trustworthiness }\end{array}$ & 3.87 & 1.69 & .08 & -.02 & -.07 & .05 & $.40 * * *$ & $.43 * * *$ & $.72 * * *$ & $.46^{* * * *}$ & $.61 * * *$ & \\
\hline $\begin{array}{l}\text { 11. Subordinate } \\
\text { performance }\end{array}$ & 0.71 & 0.46 & .00 & -.09 & -.10 & -.02 & .12 & .13 & $.32 * * *$ & .14 & $.23 * * *$ & $.44 * * *$ \\
\hline
\end{tabular}

Note. $* p<.05$ (2-tailed), ** $p<.01$ (2-tailed), *** $p<.001$ (2-tailed) $M$ and SD are used to represent mean and standard deviation, respectively. Men are coded as 1 ; Women are coded as 2; Both Perceived manager trustworthiness and Participation were manipulated, where 1 and 0 indicate the high and low conditions respectively. 


\section{Figure 1.}

Conceptual model of the trickle-down process of trustworthiness.

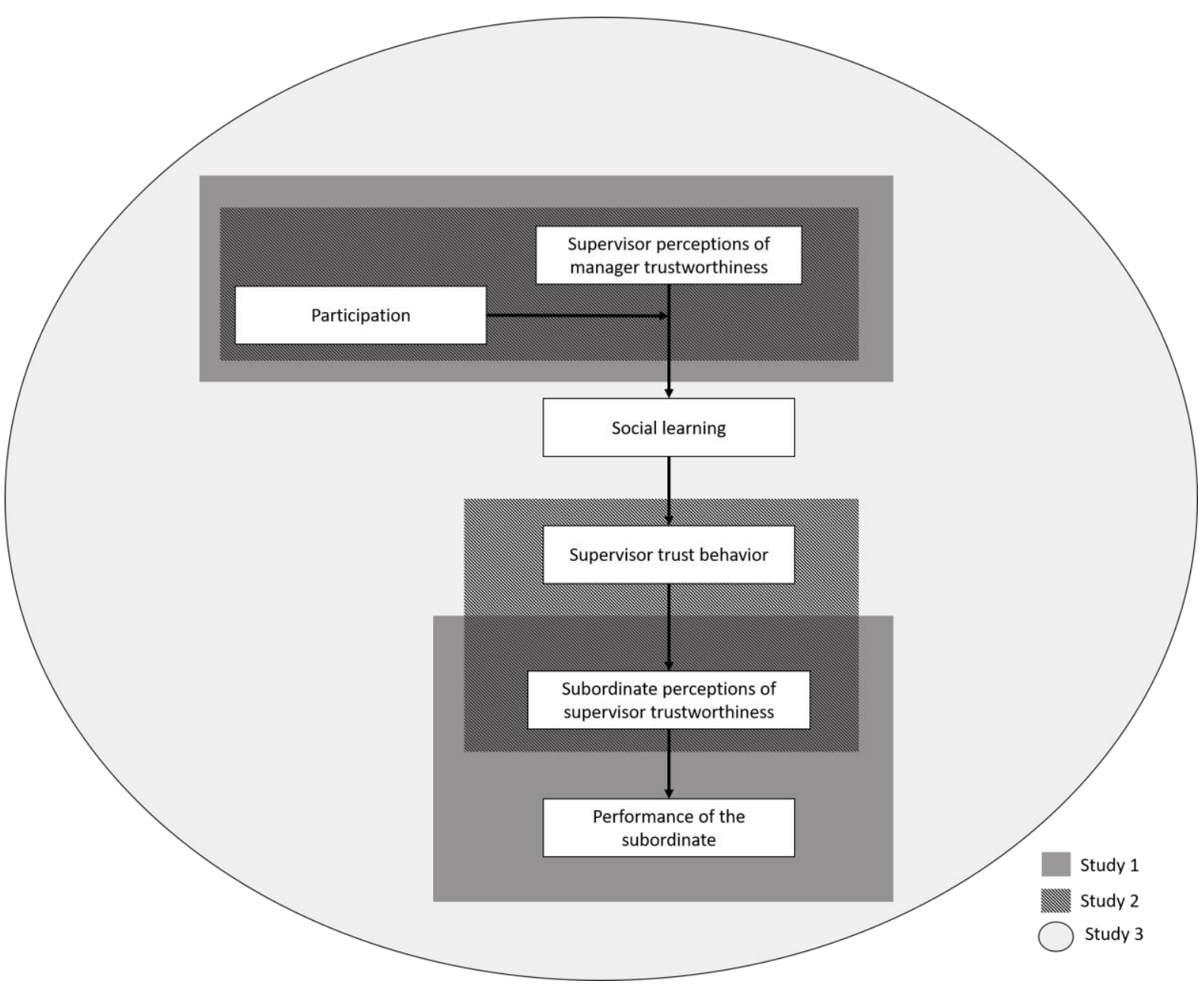

Note: The light and dark grey boxes represent the variables from the conceptual model used in Study 1 and 2, respectively. In Study 3, all variables from the conceptual model were used. 
Figure 2

The Relationship between Teacher Perceptions of Principal Trustworthiness and Student Perceptions of Teacher Trustworthiness as Contingent upon Principal Participation with Teacher (Study 1).

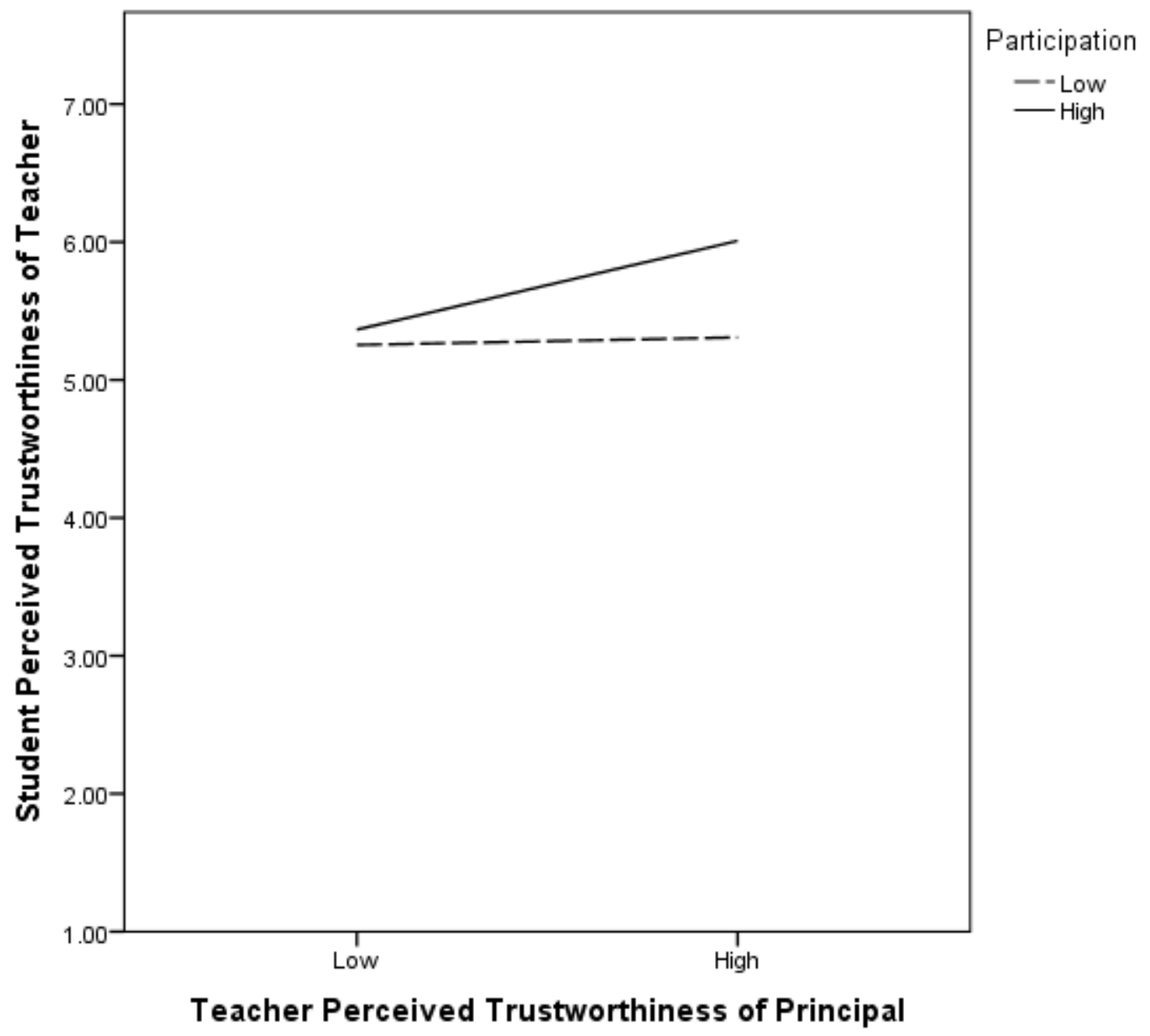


Figure 3

Region of Significance Study 1: Estimated Coefficient of Teacher Perceptions of Principal Trustworthiness on Student Perceptions of Teacher Trustworthiness by Teacher Participation in Decision-Making.

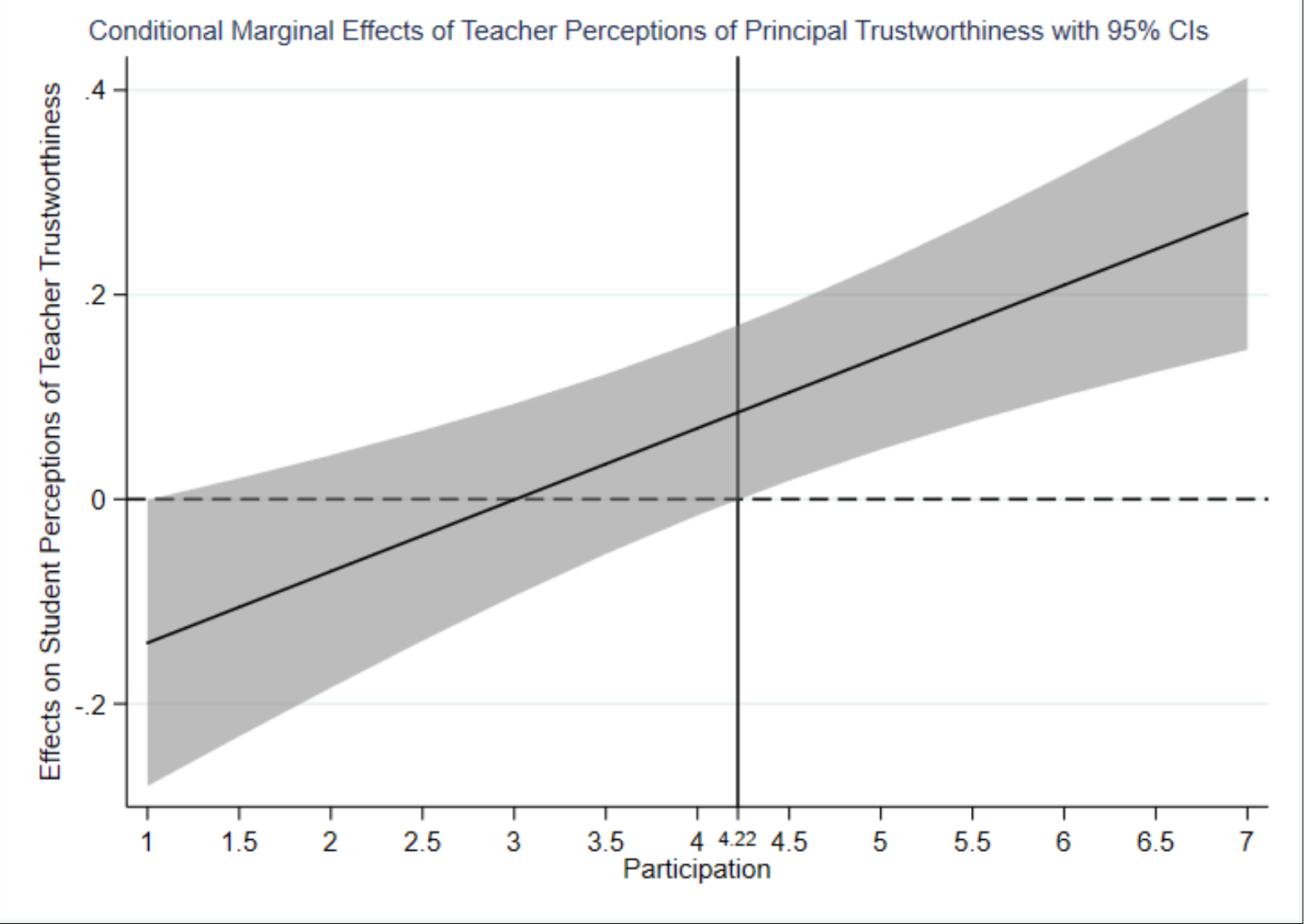

This figure shows the marginal effect of teacher perceptions of principal trustworthiness on student perceptions of teacher trustworthiness (Y-axis) across values of participation (Xaxis). Teacher perceptions of principal trustworthiness predicts student perceptions of teacher trustworthiness for Participation values $\geq 4.63$. The shaded area shows the $95 \%$ CI interval. 
Figure 4

The Effect of Perceived Trustworthiness of Manager on Supervisor Trust Behavior as Contingent upon Supervisor Participation in Decision-Making (Study 2)

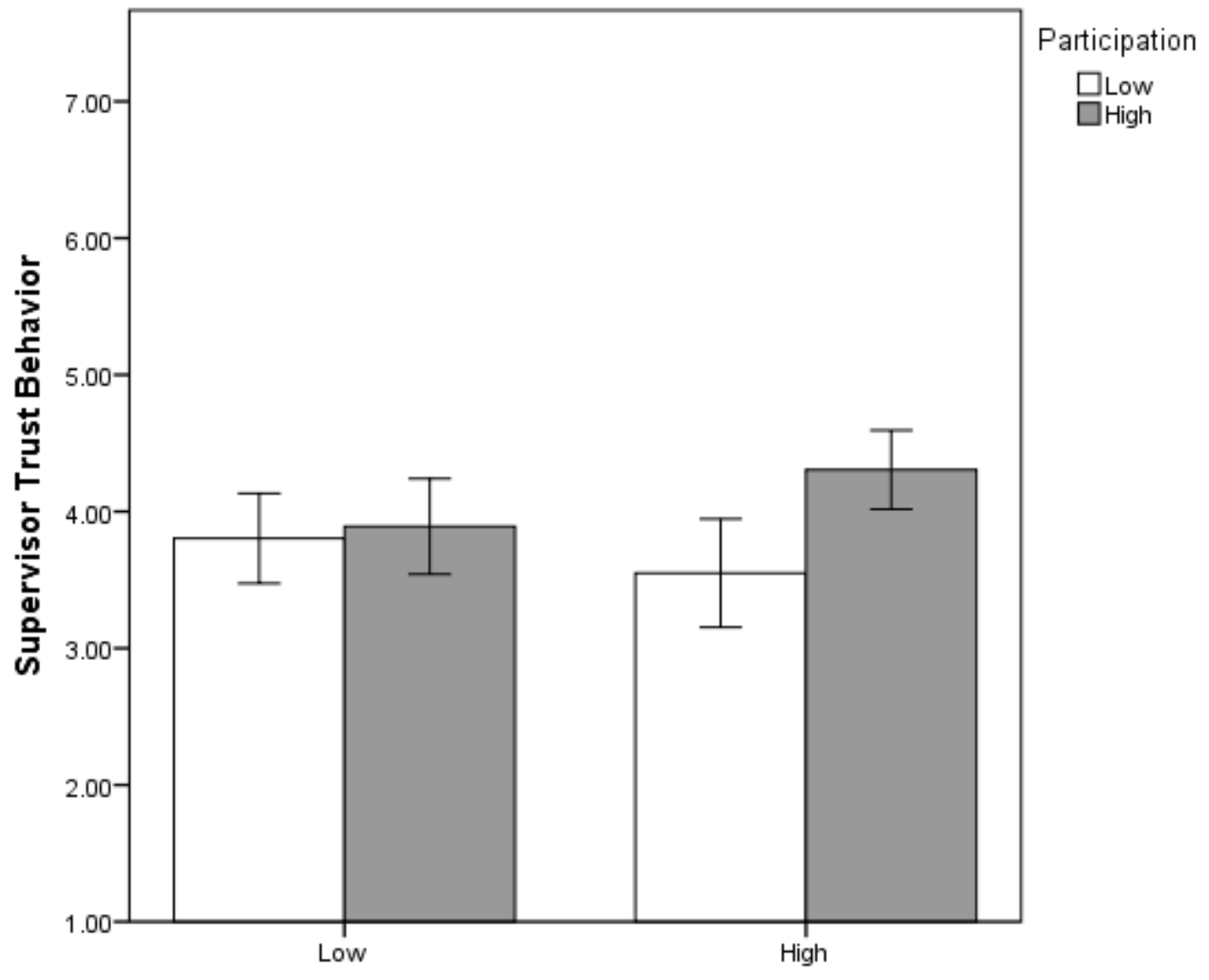

Supervisor Perceptions of Manager Trustworthiness

Error Bars: $95 \% \mathrm{Cl}$ 
Figure 5

The Effect of Perceived Manager Trustworthiness on Social Learning as Contingent upon Supervisor Participation in Decision-Making (Study 3)

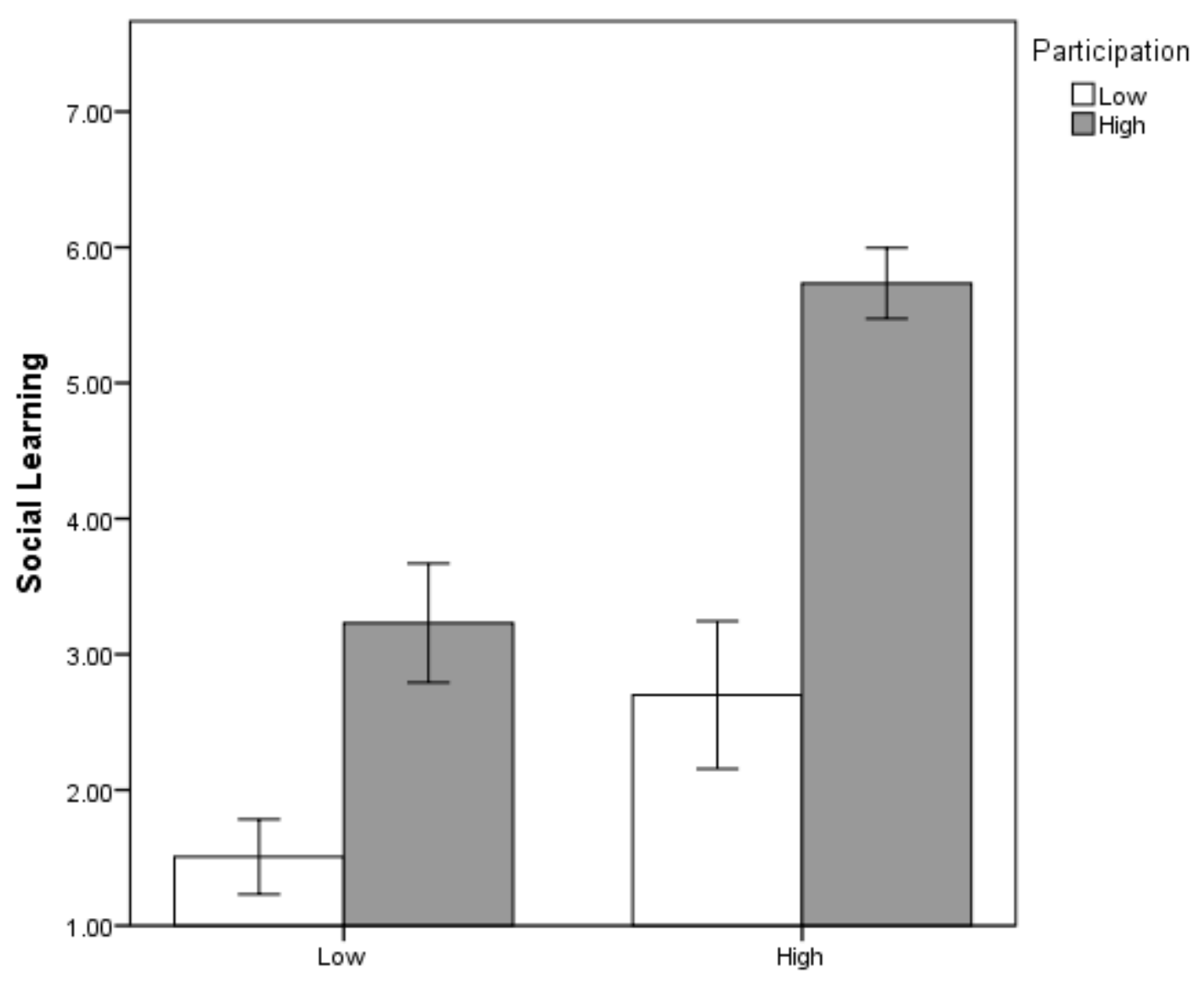

Supervisor Perceptions of Manager Trustworthiness

Error Bars: $95 \% \mathrm{Cl}$ 
Appendix A

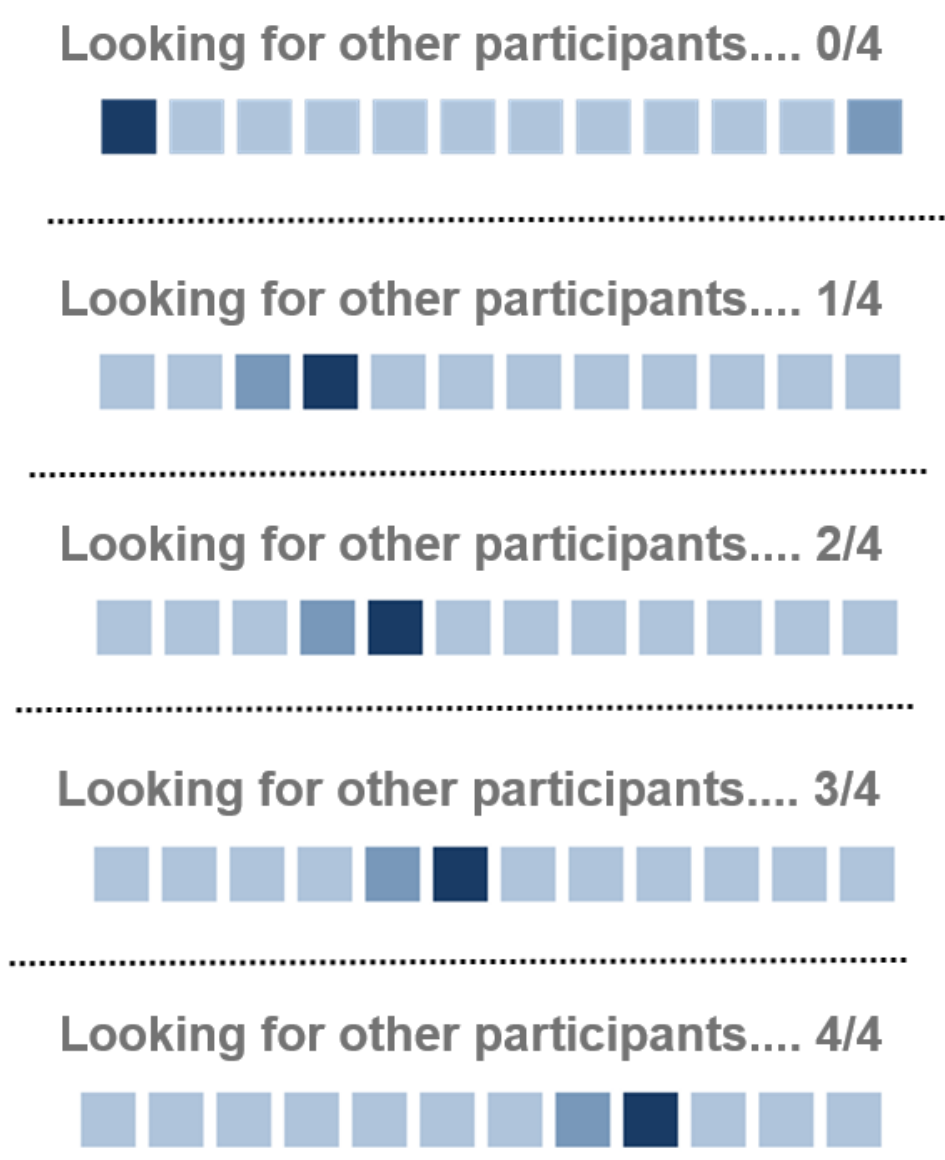

This in an illustration of the loaders that appeared on the screen of the participants. The loading bar was a gif-image where the dark blue square looped from left to right. After several seconds, the subsequent screen appeared so that participants saw that the counter (e.g., 1/4) went up. This animated progress bar made participants believe that the system is busy connecting them, and that they had to wait until the system was ready. 